\title{
The psychological impact of paediatric burn injuries: a systematic review
}

\author{
Alix Woolard ${ }^{1,2^{*}}$, Nicole T. M. Hill' ${ }^{1}$, Matthew McQueen ${ }^{1}$, Lisa Martin³ ${ }^{3}$, Helen Milroy², Fiona M. Wood ${ }^{4}$, \\ Indijah Bullman ${ }^{1}$ and Ashleigh Lin ${ }^{1,2}$
}

\begin{abstract}
Objective: To review and synthesise qualitative literature regarding the psychological outcomes following paediatric burn injuries, and to determine if children and adolescents who experience a burn injury have elevated risk of psychopathology following the injury.
\end{abstract}

Design: Systematic review of quantitative and qualitative studies.

Data sources: Informit health, Medline, Embase, and PsycINFO were searched from January 2010 to December 2020.

Data extraction and synthesis: Two reviewers screened articles, and one reviewer extracted data (with cross-checking from another reviewer) from the included studies and assessed quality using an established tool. Narrative synthesis was used to synthesise the findings from the quantitative studies, and thematic synthesis was used to synthesise the findings of included qualitative studies.

Results: Searches yielded 1240 unique titles, with 130 retained for full-text screening. Forty-five studies from 17 countries were included. The psychological outcomes included in the studies were mental health diagnoses, medication for mental illness, depression, anxiety, stress, fear, post-traumatic stress, post-traumatic growth, emotional issues, self-harm, self-esteem, self-concept, stigmatisation, quality of life, level of disability, resilience, coping, and suicidality.

Conclusions: Our findings highlight paediatric burn patients as a particularly vulnerable population following a burn injury. Studies suggest elevated anxiety and traumatic stress symptoms, and higher rates of psychopathology in the long-term. Further research is recommended to determine the psychological outcomes in the other mental health domains highlighted in this review, as findings were mixed.

Clinical care teams responsible for the aftercare of burn patients should involve psychological support for the children and families to improve outcomes.

Keywords: Burn, Pediatric, Psychological outcomes, Psychopathology

\section{Introduction}

Burns are one of the most severe injuries that a child can experience and are a common cause of emergency presentations. The most recent Australian annual report showed 5430 cases of hospitalisation for burns, the

\footnotetext{
*Correspondence: alix.woolard@telethonkids.org.au

${ }^{1}$ Telethon Kids Institute, Perth Children's Hospital, 15 Hospital Avenue, Nedlands, Australia

Full list of author information is available at the end of the article
}

majority of which were young children (aged 0-4) [1]. Paediatric burn management and medical aftercare has made significant advances in recent decades (for a review, see; [2]), such that current survival rates are high for even very serious burns $[3,4]$. Historically, burn aftercare has focused on physical healing, in recent years, however, research has uncovered the poor psychological outcomes in children who experience burns, including a minor burn injury [5]. This is because burn injuries do not only have a serious physical impact on a child, they also 
seriously impact the psychological and emotional wellbeing of the child and their family.

Burn injuries are painful, both physically and mentally. This is especially the case for young children who may not understand that procedural pain (e.g., dressing changes) is a necessary component of recovery [6]. In fact, early burn studies provided some of the founding research for the original clinical outline of posttraumatic stress disorder (PTSD) in the Diagnostic and Statistical Manual of Mental Disorders-III [7, 8]. The event in which the injury occurred is often traumatising [9], and hospitalisation can be scary for children and often involves separation from family or peers, which is traumatic in itself [10]. Further, the immediate and subsequent wound care following a burn injury is not only physically painful, but also invasive and pervasive [11]. Scarring is also common for a burn wound, despite medical advances, which requires long-term medical care and can also contribute to poor psychological outcomes [9].

Given the severity and prevalence of paediatric burn injuries, as well as the accompanying trauma during and after a burn, there is a need to address the psychological after-care of paediatric burns. Symptoms of PTSD are often reported in children who have experienced a burn injury [12-14]. Other studies have also found that postburn, individuals can report high rates of acute stress disorder [15], anxiety, and depression [9].

It is important when attempting to address clinical outcomes, such as the psychological after-care of paediatric burns, to first review the available evidence on the subject and make evidence-based evaluations. The existing reviews of paediatric burn outcomes reveal that the majority of children who have experienced paediatric burn injuries often go on to experience long-term psychopathology [16-18]. There are studies that contradict these findings, with reports of children adjusting well after this injury [19]. However, the most recent review on psychopathology following paediatric burns, conducted 8 years ago, found that the overwhelming majority of studies report short- and long-term psychopathology in both children and their parents after a burn injury [10]. This review highlighted that the majority of children who have experienced a burn injury go on to display some sort of distressed behaviour, either internalising (such as anxiety and withdrawal) or externalising (such as aggression and opposition) behaviours [10]. The findings highlight the importance of psychological aftercare and how advances in mental health care following a burn injury had greatly improved between 2000 and 2012, giving clinicians a better understanding of the broader needs of those who have experienced paediatric burns [10].

There is a need for an updated review of the work by Bakker et al. [10] of the current research on the psychological impact and outcomes of paediatric burns. Clinicians need to be aware of the current research on the psychological outcome of paediatric burns survivors to be able to target areas of need - which extend beyond treating the physical burn. The aim of this current review was to search, review, and evaluate the current research that has been conducted on the psychological impact on children's mental health following paediatric burn injury. The primary objective of this study was to examine the research (conducted in the last 10 years) that exists on the psychological impact on children's mental health following a paediatric burn injury. We hypothesised that children or adolescents who sustained a burn injury would be more likely to go on to experience psychopathology than those who had not experienced a burn injury.

\section{Method}

We conducted this review following the Preferred Reporting Items for Systematic Reviews and MetaAnalyses (PRISMA) statement guidelines [20]. Our review methodology was registered with the PROSPERO international prospective register of systematic reviews (CRD42020215553, National Institute for Health Research, n.d.).

\section{Search strategy}

Electronic databases Informit health, Medline, Embase, and PsycINFO were searched on the 19th of October 2020, for English-language empirical peer-reviewed articles published in the last 10 years (2010-2021). Our search terms included: 'children', 'chil"', 'paediatric', 'pediatric', 'youth, 'young, 'adolesc", AND 'burn"', 'thermal"' AND 'psycholog"', 'psychopathology', 'mental health', 'depression', 'anxiety'. These terms were derived from our research question, similar published reviews, and through consultation with experts in the field. Additional articles were identified through comprehensive hand searches of the reference lists of included articles and Google Scholar searches. Two authors (AW, NTMH) conducted the initial screening of abstract and titles, and the full-text screen of potential articles. Any discrepancies were resolved by two authors (AW, AL).

\section{Inclusion and exclusion criteria}

Articles were included if they involved: 1) data on the psychological impact or psychological outcome of paediatric burn injury, 2) mean age of children in the study was under 18 years of age at the time of the burn injury, 3) the injury involved a burn that required hospitalisation (including emergency presentation). Psychological outcomes were reported from parent-report or caregiverreport questionnaires, child self-report questionnaires, or from observational assessment. Cross-sectional or 
cohort studies were eligible if the psychological outcomes were assessed after the burn injury. Randomised control trials (RCTs) were eligible if psychological measures were assessed at baseline (pre-intervention). Eligible control groups included child or adolescent populations that did not experience a burn injury.

Articles were excluded if they; 1) only included physiological or functional outcomes of the child only, 2) articles with adult populations, 3) papers not peer-reviewed (e.g. grey literature and book chapters), 4) intervention studies that focussed on a drug or behavioural treatment of the burn injury and did not measure psychological variables at baseline, 5) psychological outcomes related to parents of the child only, 6) burn injury arose from selfharm, potentially indicating prior psychopathology, and 7) burn injury was reported as the result of intentional harm (such as maltreatment by a caregiver). Non-English language studies were included and translated using Google translate. The first author contacted authors for further details (e.g., unpublished data, further information from abstracts) on grey literature to avoid publication bias.

\section{Data collection, risk of bias and quality assessment}

Data were extracted using the software Covidence [21], which has a data extraction template. Results were reported according to the PRISMA statement (Liberati et al., 2009). Study quality was assessed using the National Heart, Lung and Blood Institute quality assessment tool for observational, cohort and cross-sectional studies, with the addition of the following criteria relevant to this review: (1) the study involved a comparison groups: a paediatric burn group and a control non-burn group; (2) reliable and validated psychological outcome measures were used; (3) a statistical power analysis was conducted to determine optimal sample size to find differences between groups; (4) appropriate statistical analyses were conducted to determine differences between groups; and (5) the study used a prospective design rather than a cross-sectional design [22]. The quality assessment tool provides a rating for each study based on 14 criteria relating to the study population selection, blinding, confounding, outcome measures, and missing data or attrition. One reviewer (AW) rated each study using this tool, another author cross-checked (NTMH), and any discrepancies were sent to a third independent reviewer (AL) for deliberation.

\section{Results}

\section{Study selection and characteristics}

Forty-five studies we included in the review. Study selection was summarized using the PRISMA chart in Fig. 1. Study characteristics are outlined in Table 1 . The studies comprised 32 mixed method, 10 interventions, and four qualitative. The age ranges of the children at the time of the burn injury varied in each study and ranged from 0 to 18 years of age. The settings of the studies included the United States $(n=17)$, Australia $(n=12)$, Sweden $(n=3)$, Canada $(n=2)$, the United Kingdom $(n=1)$, South Africa $(\mathrm{n}=1)$, Nicaragua $(\mathrm{n}=1)$, Mexico $(\mathrm{n}=1)$, Iran $(n=1)$, Poland $(n=1)$, Switzerland $(n=2)$, Finland $(\mathrm{n}=1)$, Brazil $(\mathrm{n}=1)$, Spain $(\mathrm{n}=1)$, the Netherlands $(N=1)$ and Turkey $(\mathrm{n}=1)$. The psychological outcomes included in the studies were mental health diagnoses, medication for mental illness, depression, anxiety, stress, fear, post-traumatic stress, post-traumatic growth, emotional issues, self-harm, self-esteem, self-concept, stigmatisation, quality of life, level of disability, resilience, coping, and suicidality. Eighty-eight per cent of studies used validated and standardised assessments.

\section{Results of quantitative studies \\ Anxiety}

The most commonly reported psychological outcome in this review was anxiety in children and adolescents following a burn injury [23-37]. The six cohort studies investigating the presence of anxiety following a pediatric burn examined children with burns versus normative data on uninjured children, or how anxiety related to differing individual factors in the child or adolescent population, such as age or gender. One study compared the anxiety of children or adolescents who had been hospitalised for burns for at least 24-h to normative data and found that state (i.e. situational) and not trait (i.e. related to personality) anxiety was higher in children and adolescents who had experienced a burn injury [31]. Another study that explored anxiety and pain found that pain was significantly associated with anxiety in children or adolescents who had been discharged from hospital for a burn 6-12 months prior [30]. One study investigating age of the child at injury found that age was significantly related to anxiety, with pre-school children exhibiting more anxiety around wound dressings than older children [25]. Rimmer et al. [34, 35] conducted two studies investigating anxiety in burn-injured children and adolescents; one study examined concordance of parent and child ratings of anxiety, and one study investigating anxiety levels generally. Children self-reported their anxiety levels as significantly higher than proxy-reports by their parents [35]. A high proportion of children and adolescents screened positively for anxiety symptoms (39\%), with $28 \%$ of the population scoring above the cut-off to indicate an anxiety disorder. This is compared to $6.9 \%$ of Australian children in the general population $[34,38]$. This study also observed that girls with a burn injury scored higher on anxiety measures than boys [35]. 


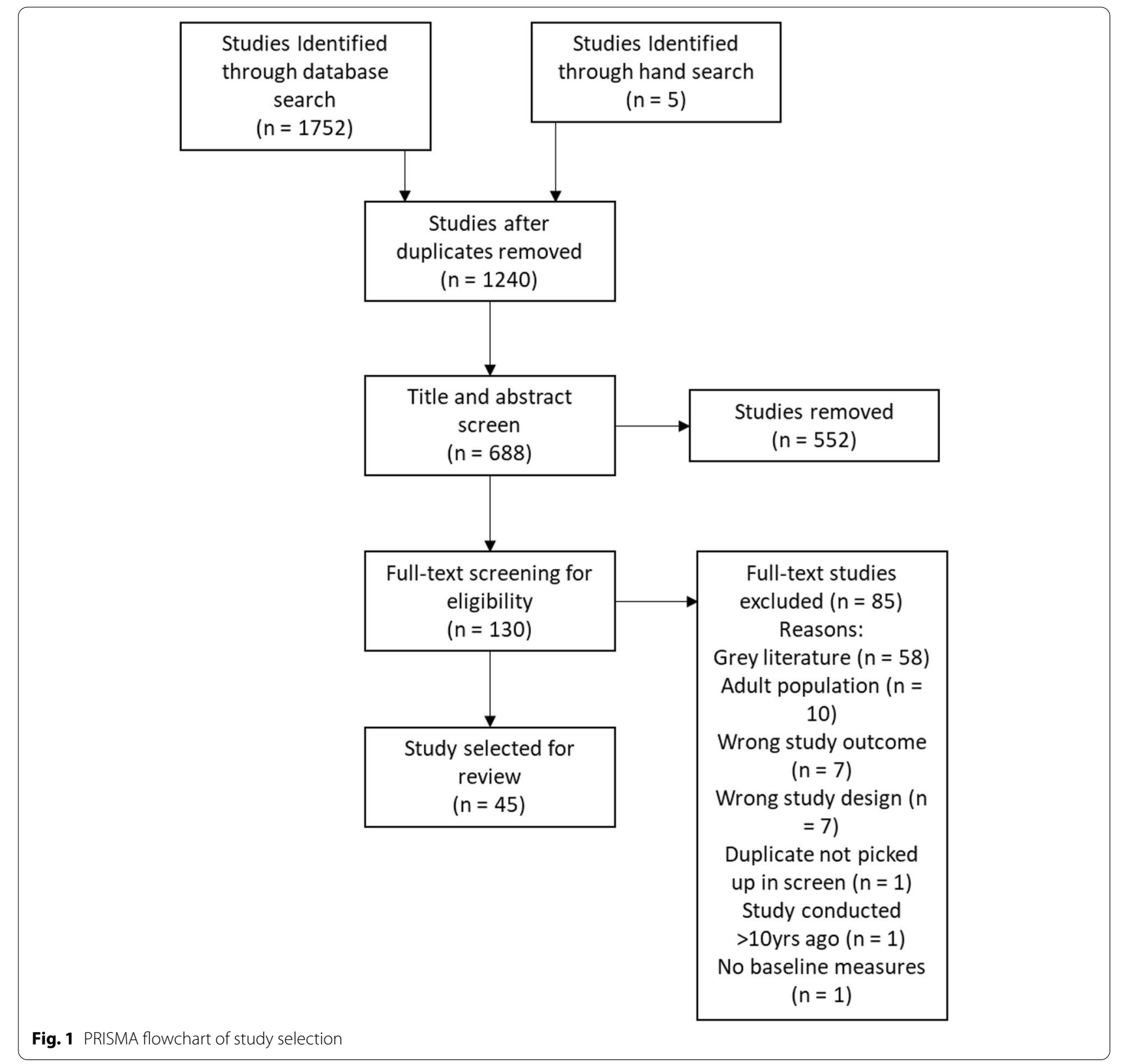

Riobueno-Naylor et al. [36] found that children who reported concerns with their appearance after burn were more likely to have social anxiety compared to those who had no appearance concerns, regardless of burn size, bodily location of burn or gender of the child.

There were nine RCTs that investigated anxiety and pediatric burns [23, 24, 26-29, 32, 33, 37]. Three of the studies used the Visual Analog Scale - Anxiety (VASA), which has not been validated in a control group for children, however baseline anxiety was comparable for all children with burn injuries in all three studies $($ mean $=2.6-2.76[23]$; mean $=2.7-2.9[24]$; mean $=2.0$
[27]). One of the studies used a measure of anxiety that was created specifically for the intervention (Yoga Evaluation Questionnaire), and thus is not able to be compared to normative data [26]. Khadra et al. [29] found that children's anxiety (indexed on the Procedural Behaviour Checklist [39]) was low at baseline, but was strongly positively related to procedural pain and fear. Jeffs et al. [28] reported that the children in their study at baseline scored an average of 31.5 (state) and 34 (trait) on the State-Trait Anxiety Inventory [40], which is just below the clinical cut-off for an anxiety disorder [39, 41]. Conversely, Parlak-Gurol et al. [32] reported much higher 


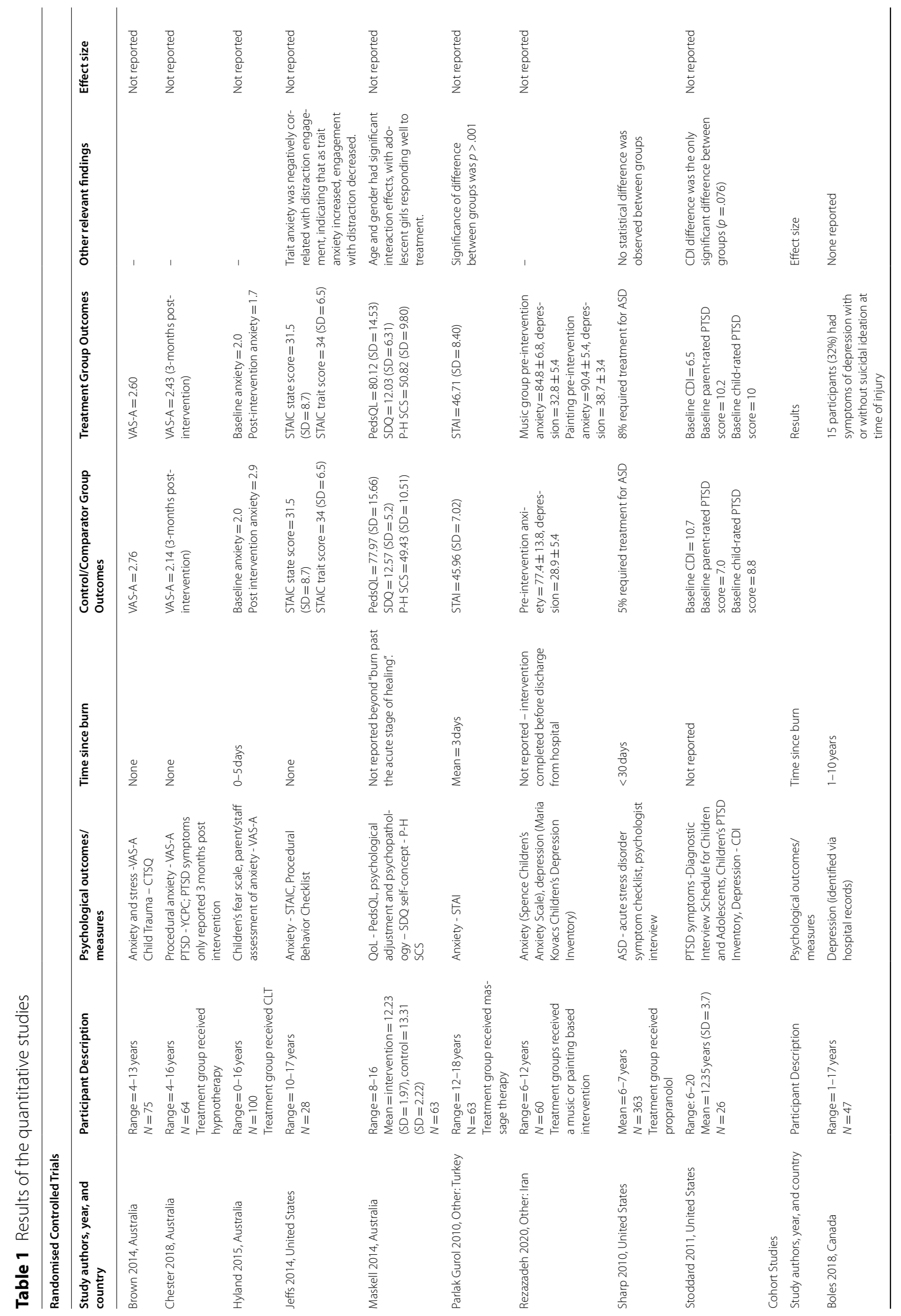




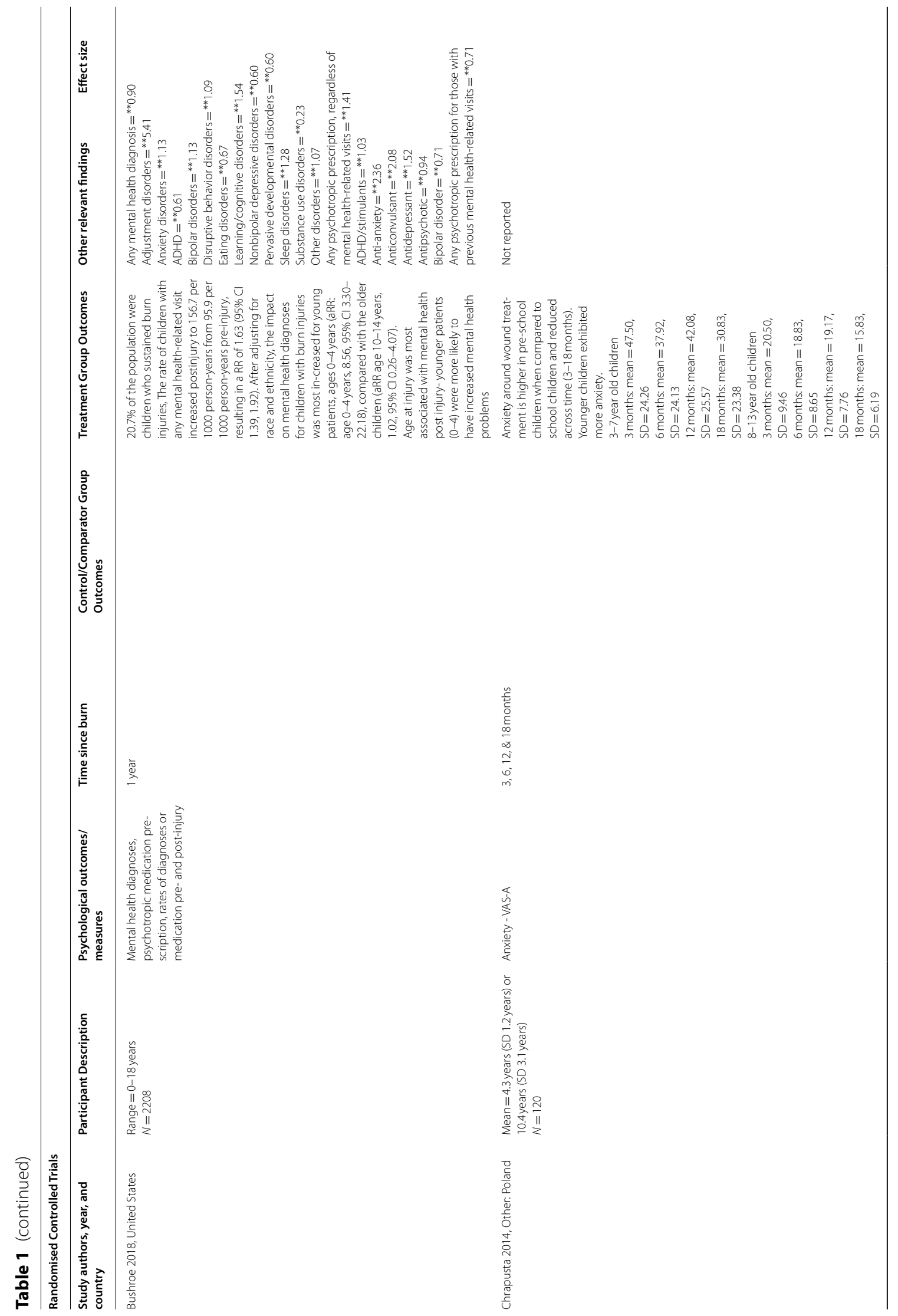




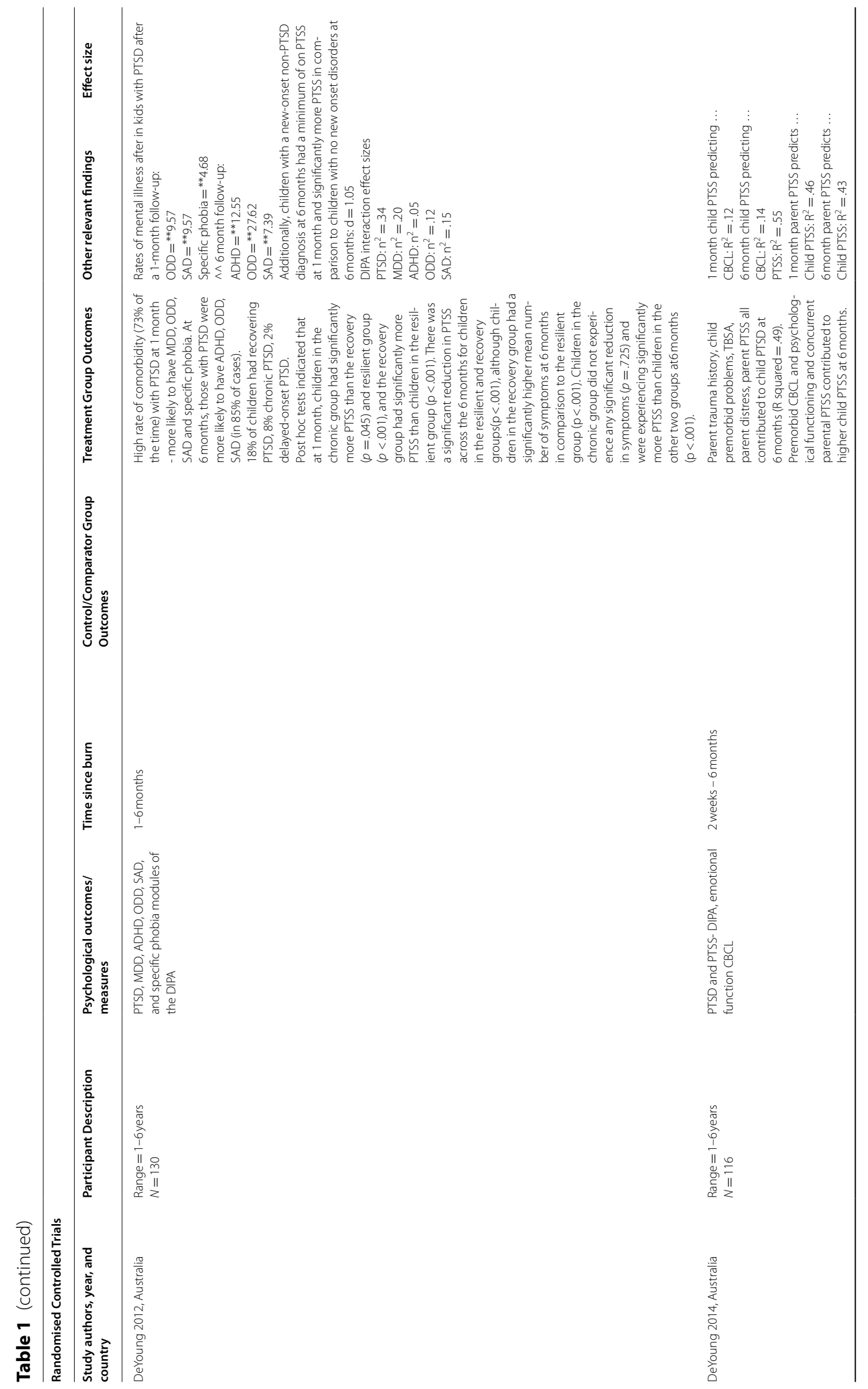




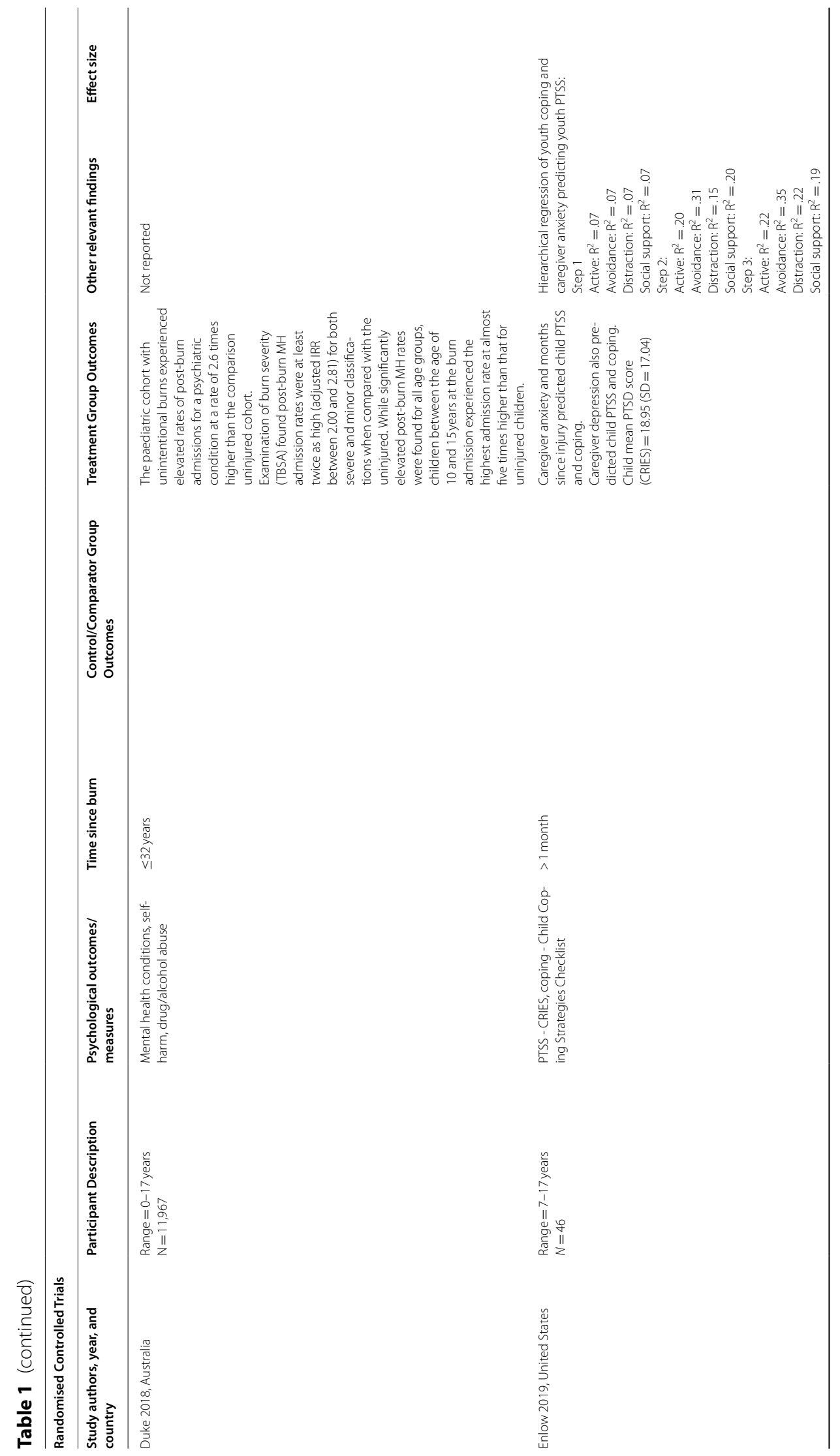




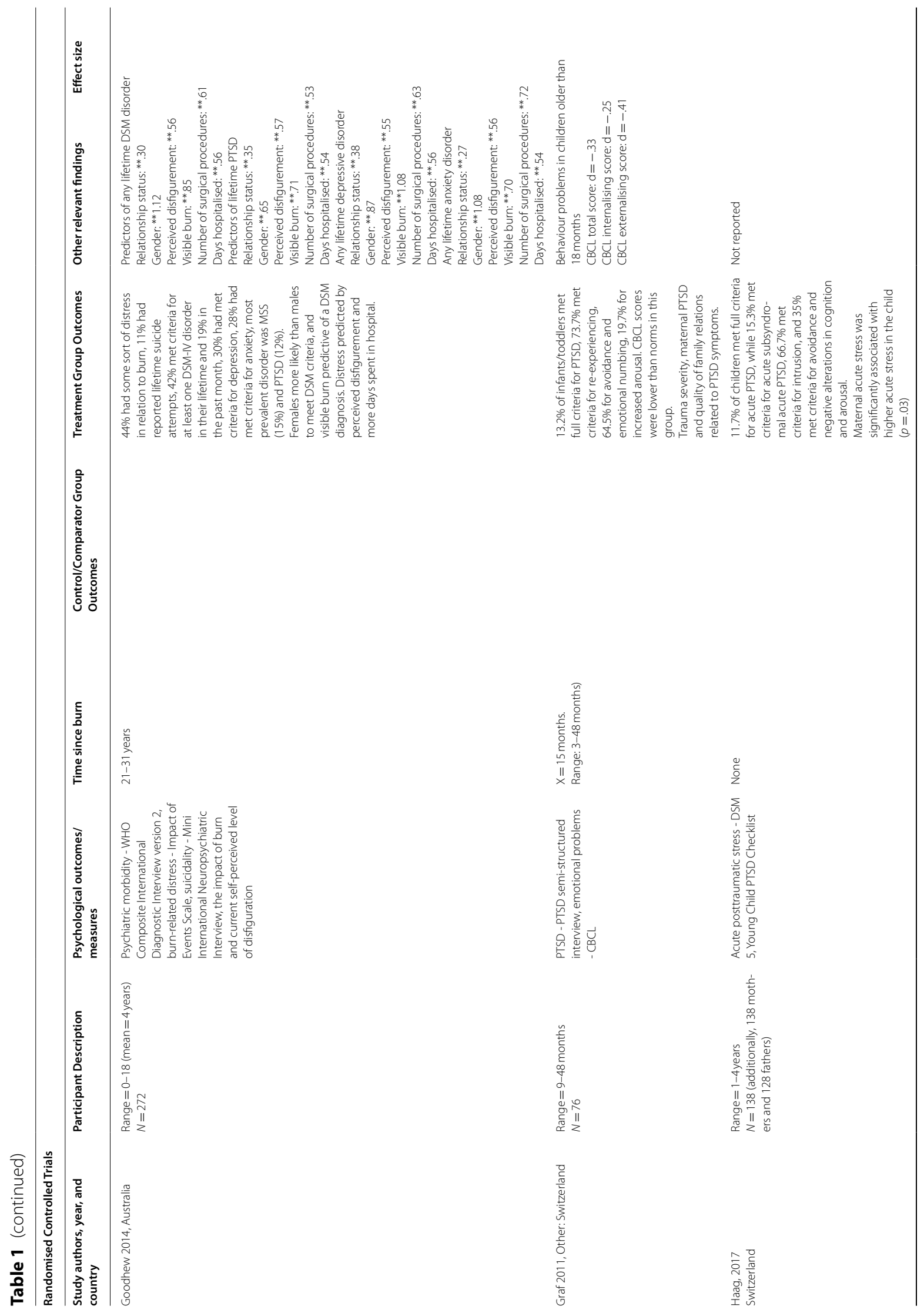




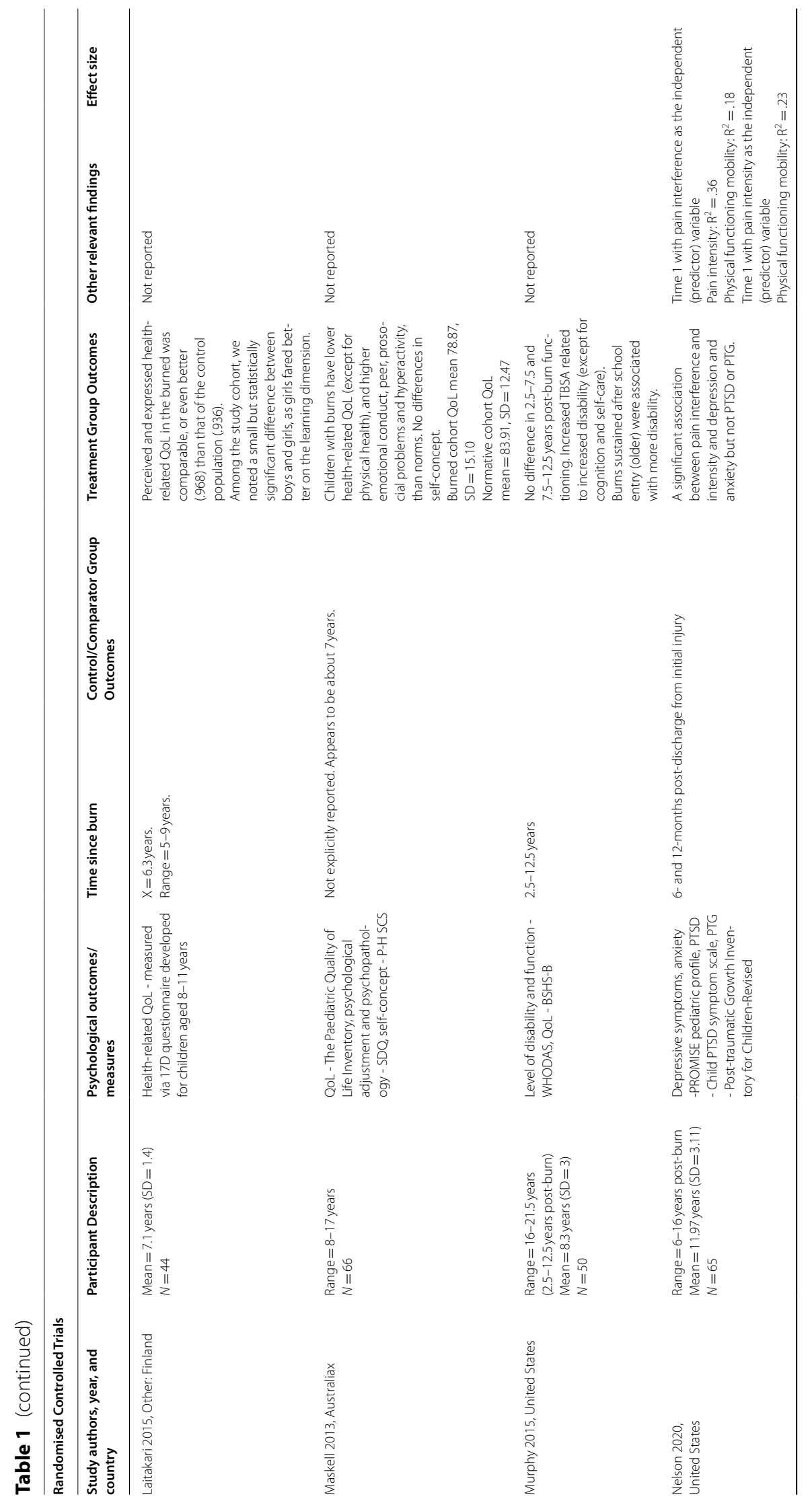




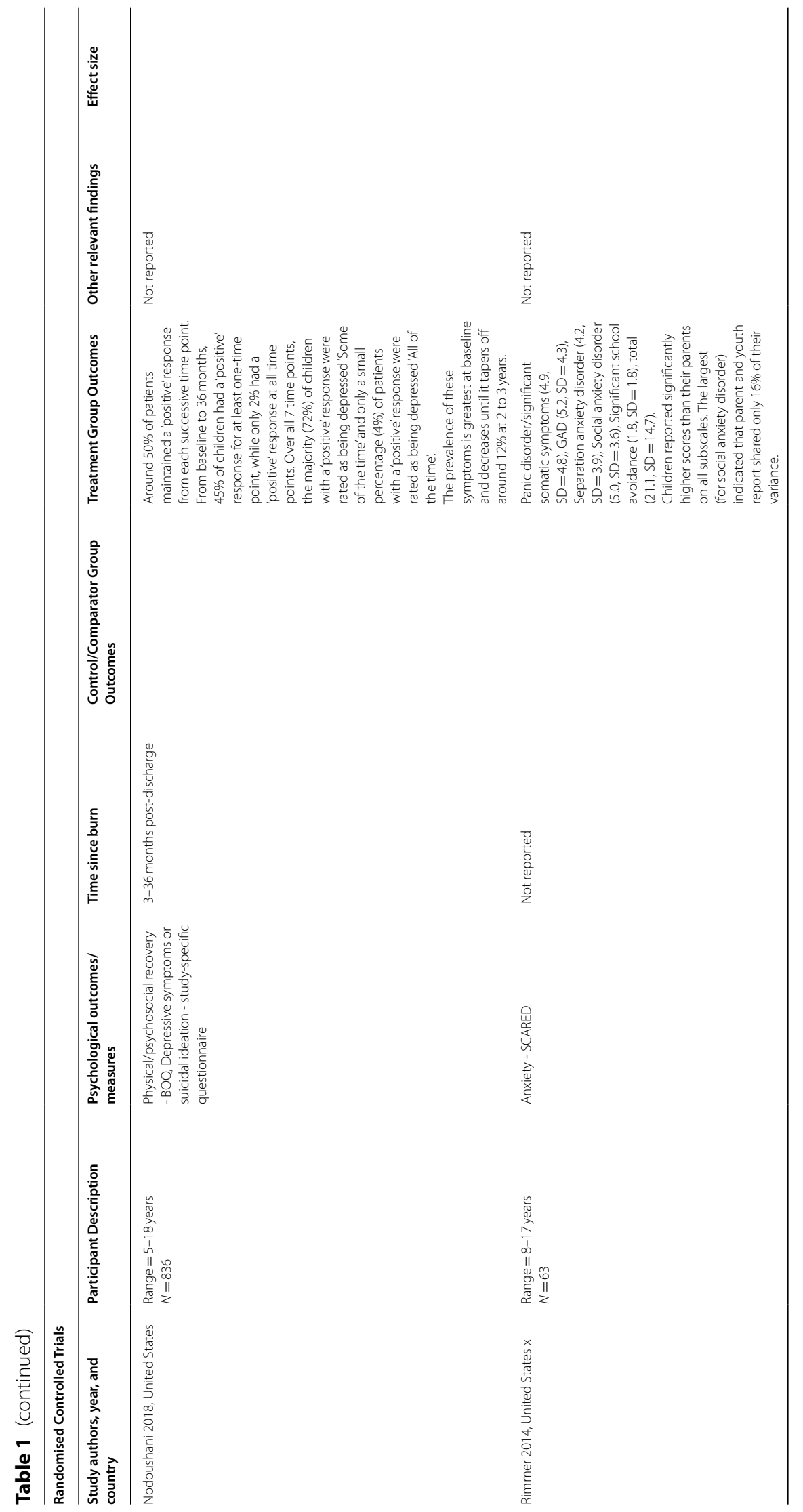




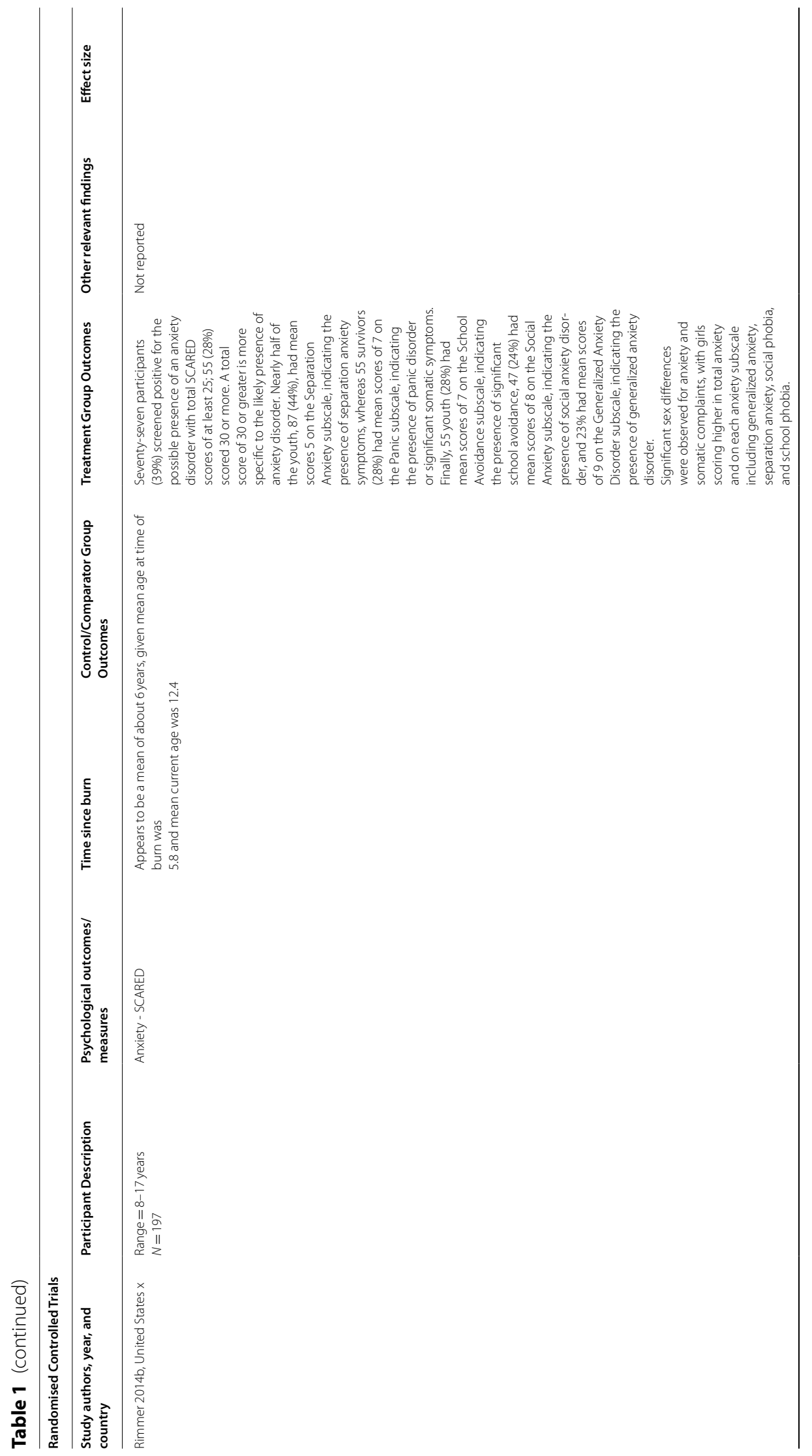




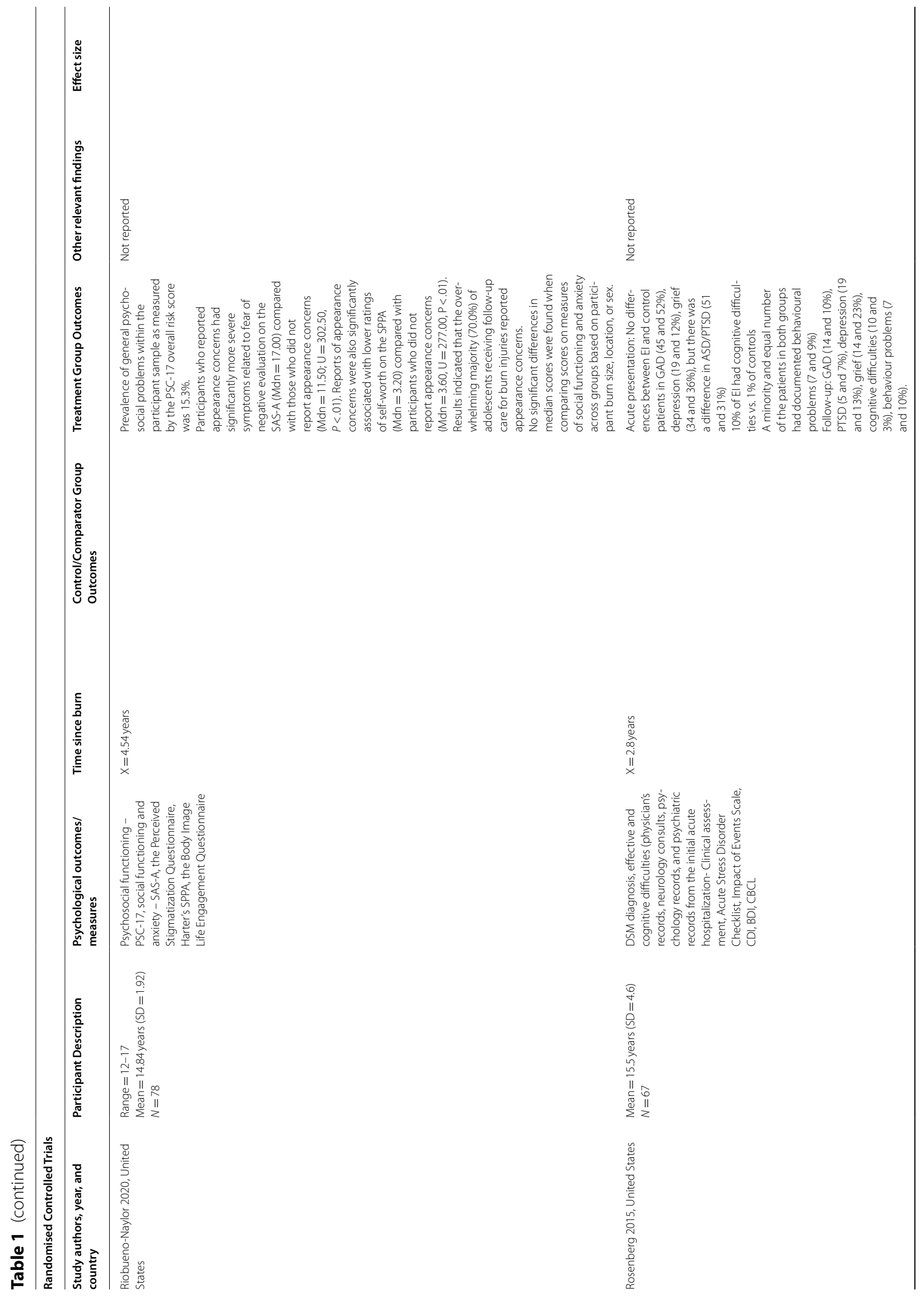




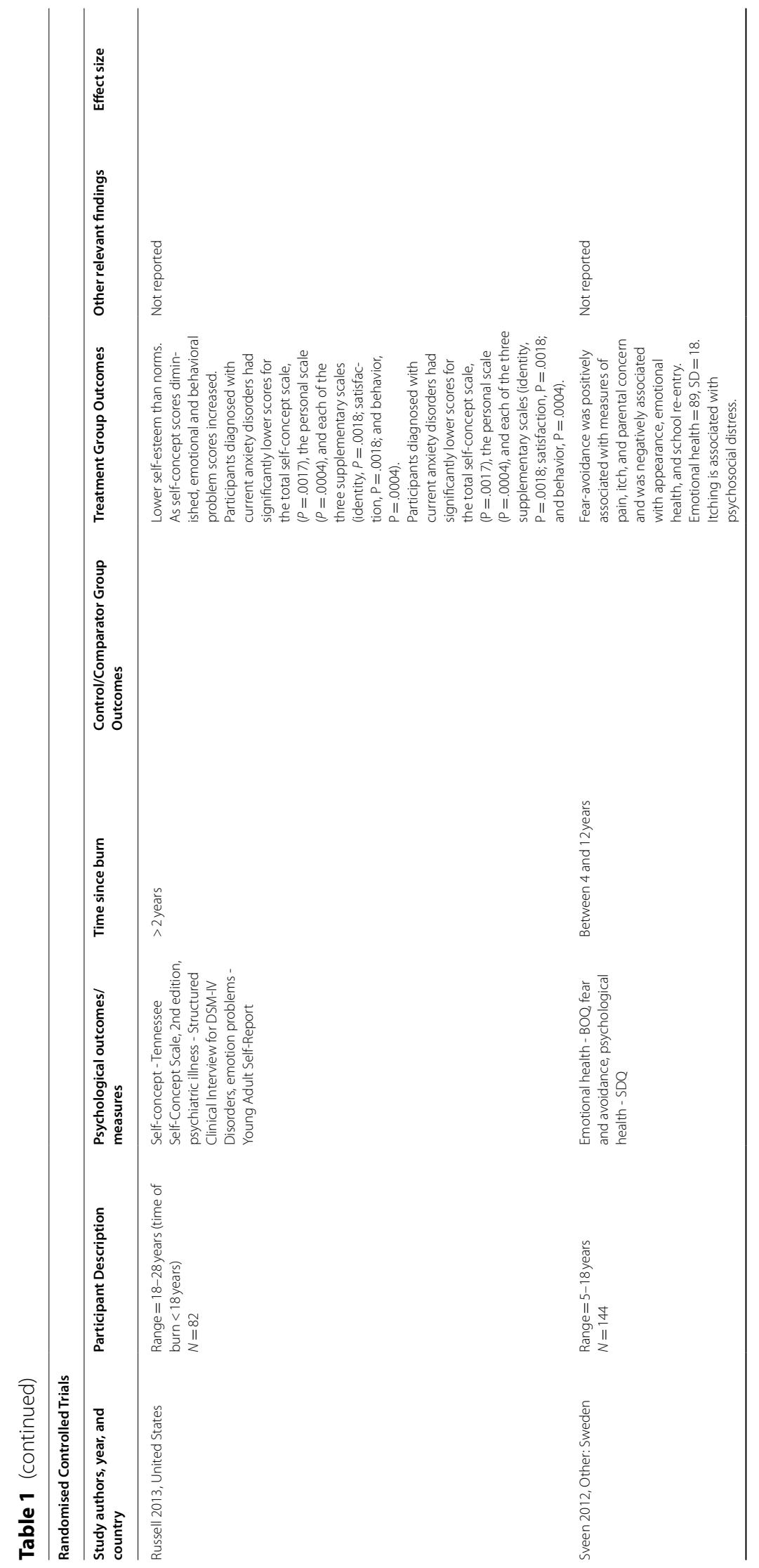




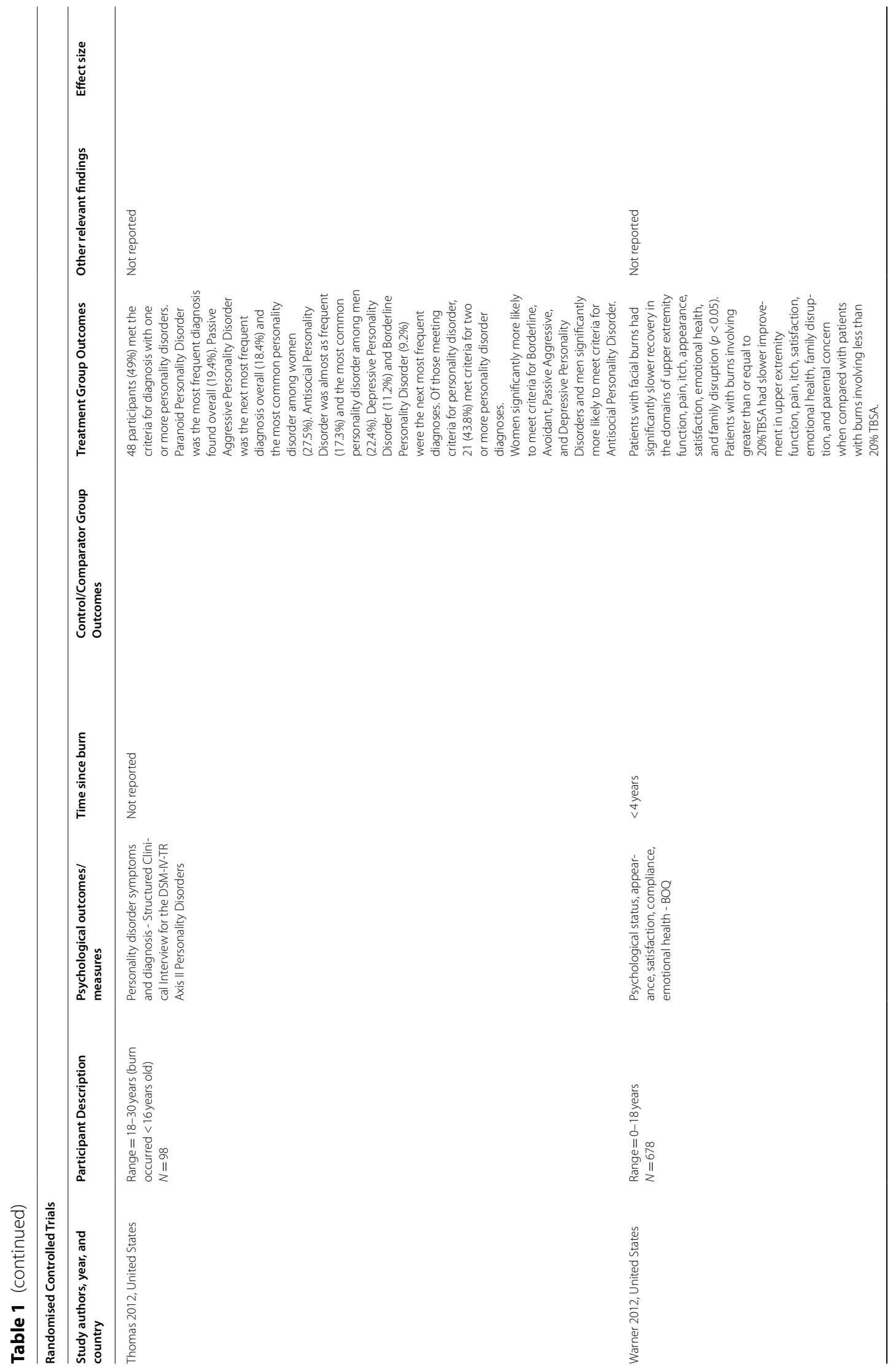




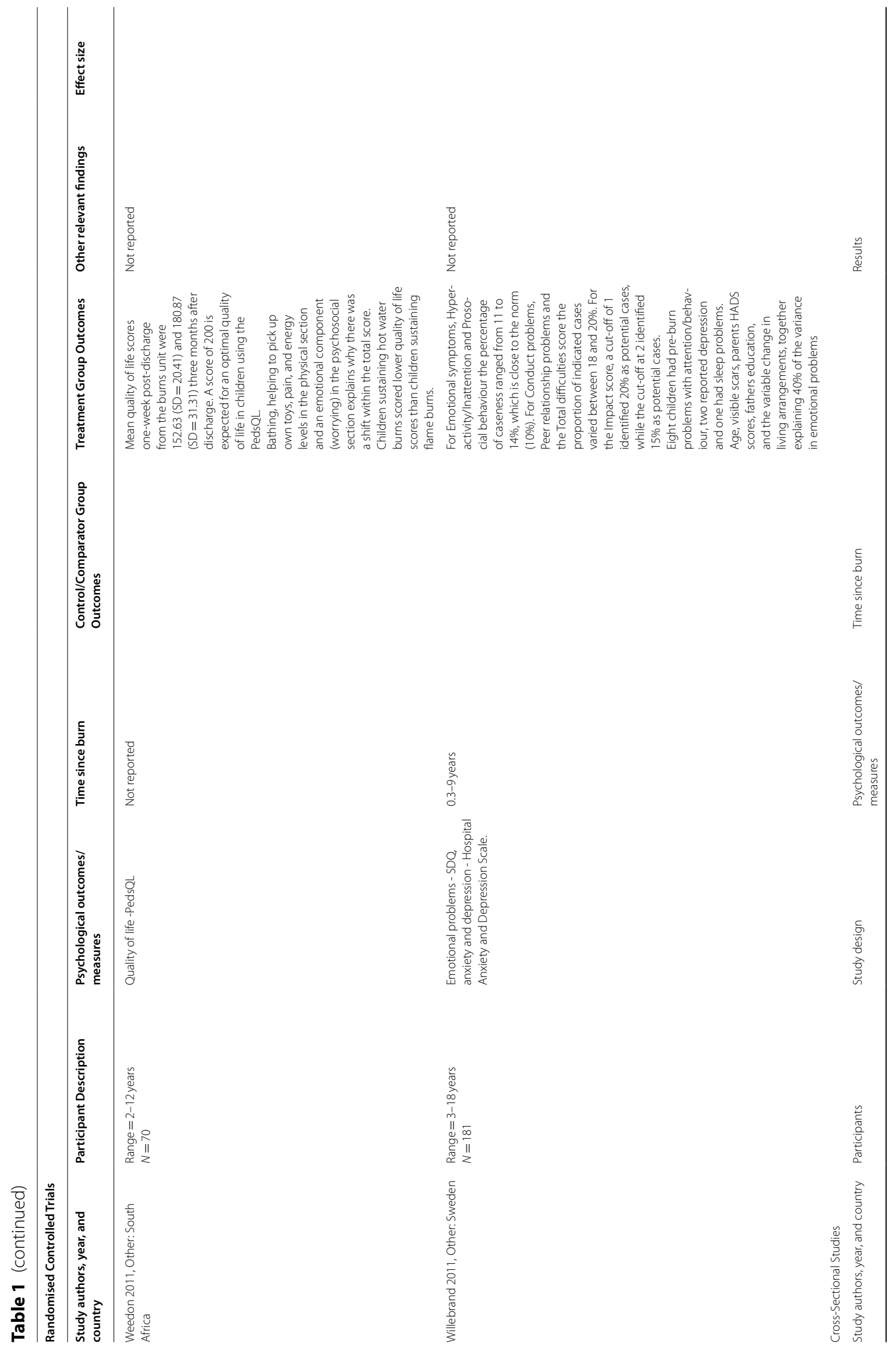




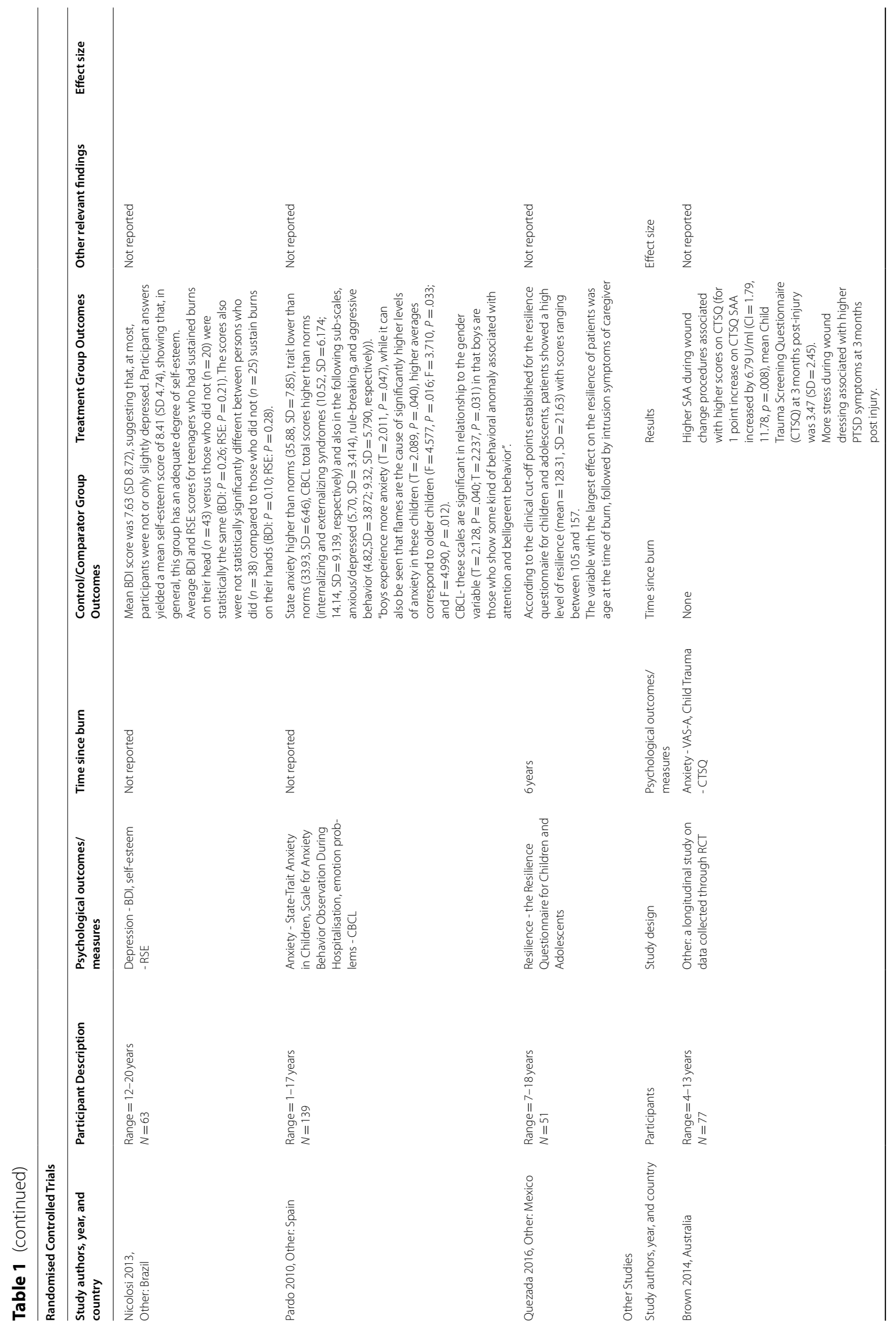




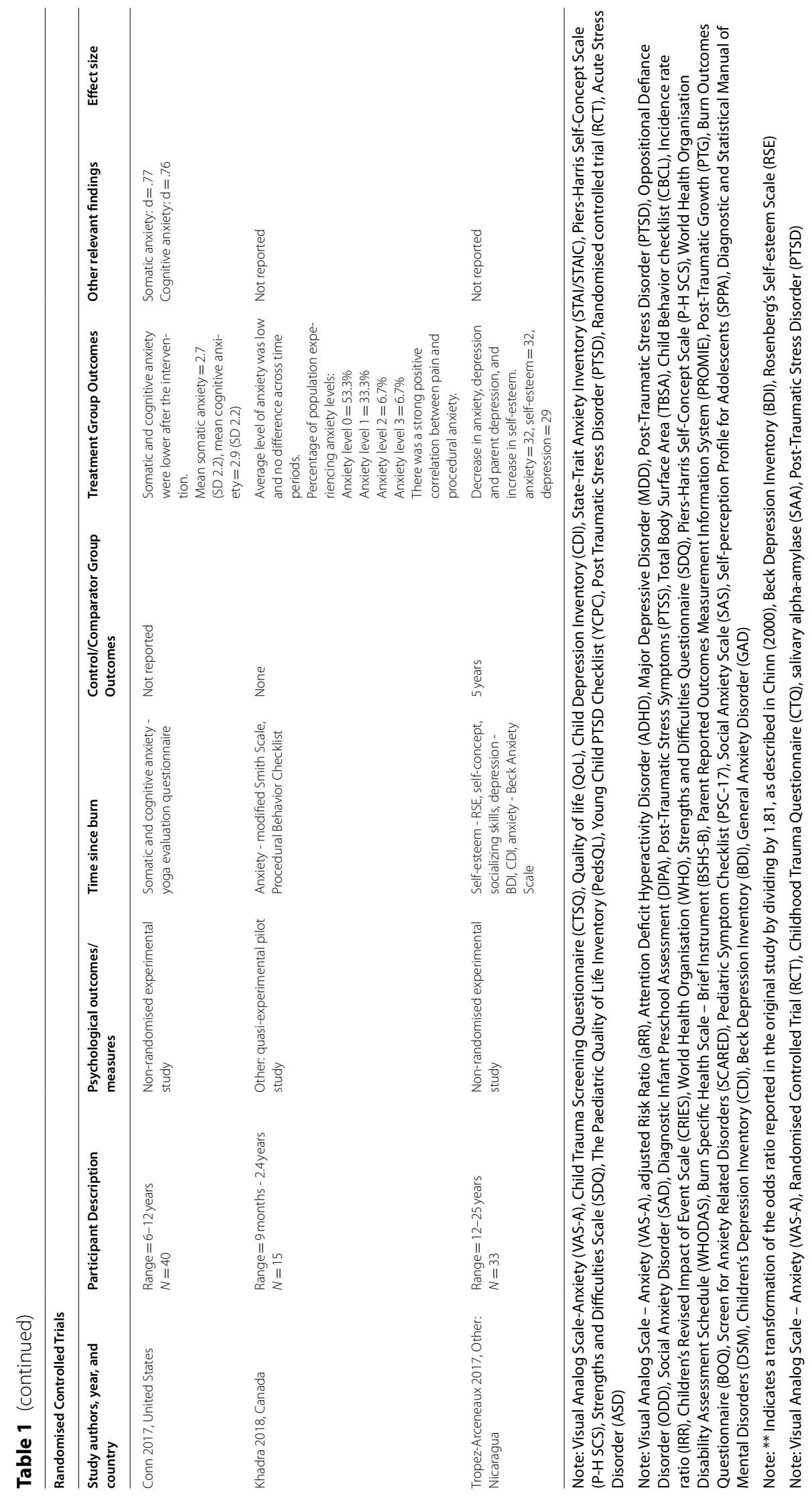


baseline scores (range $=46.71-45.96$ ) for state anxiety using the same measure, placing their cohort in the clinical range. One study found that children recovering from a burn injury had a baseline score of 32 on the Beck Anxiety Inventory [42], which indicates severe anxiety [37]. Finally, another RCT reported that the children in their study scored at baseline much higher on the Spence Children's Anxiety Scale [43] than what is reported in normative studies (77.4-90.4, compared to 21.72, respectively; [33]). In summary, anxiety was consistently identified as a common outcome of pediatric burns. This relationship was replicated across multiple studies of differing methodological quality, with age, gender, perceived bodyimage, procedural pain, and fear noted as influential factors.

\section{Traumatic stress}

Another common psychological outcome investigated in the literature was traumatic stress or post-traumatic stress symptoms [24, 30, 44-50]. One study found that $8 \%$ of children required treatment for Acute Stress Disorder after their burn injury [49]. Another study examining PTSD symptoms found that $11.7 \%$ of children met full criteria for PTSD, and a further 15-66.7\% met subclinical thresholds for at least one cluster of symptoms (i.e. reexperiencing the event, avoidance, emotional numbing or increased arousal) [48]. Similarly, Graf et al. [47] found that $13.2 \%$ of toddlers in their study (aged 9-48 months) met full criteria for PTSD, and between 19.7-73.7\% met criteria for at least one cluster of PTSD symptoms. This study also found that the burn severity and quality of family relations were all associated with toddler PTSD symptoms [47]. Several of the studies also found that maternal or parental distress and PTSD symptoms were associated with child PTSD or traumatic stress [45-48]. Brown et al. [44] showed that the stress the child experienced during wound dressings were associated with higher PTSD symptoms 3 months post-injury. De Young et al. [45] found that parental trauma history, child premorbid problems, and burn severity and size were related to child PTSD symptoms 6 months after the injury. In contrast, Nelson et al. [30] found no significant associations between pain and intensity of the burn and PTSD symptoms. Finally, Stoddard et al. [50] found that PTSD symptoms decreased gradually over time for children who had experienced a burn.

\section{Depression/mood disturbances}

Eight studies investigated depression symptoms in children after a burn injury [30, 33, 37, 50-53]. Boles et al. [51] found that $32 \%$ of their sample of children who had experienced a frostbite burn had symptoms of depression at the time of the injury. Nodoushani et al. [52] found similarly high rates of depressive symptoms in their study, with around $45 \%$ of participants indicating they felt depressed at some point in the 36 months after their injury, although these results were found using a study-specific questionnaire that has not been validated. Three studies used the Child Depression Inventory [54] to assess depressive symptoms in their samples. The first found scores to exceed the clinical cut-off for depression immediately after hospitalisation [33], with similar high scores in a the same sample 5 years post-burn injury [37]. In contrast, the third study showcased scores that were below the clinical cut-off during hospitalisation [50]. Another study by Nicolosi et al. [55] found that mean depression scores in their sample indicated that most participants were not depressed or displayed only a few symptoms of depression post-burn injury, regardless of where the burn was situated on the body. In contrast, Rosenberg et al. [53] found that $19 \%$ of patients with electrical burns had a diagnosis of depression 3 years post-injury. Finally, Nelson et al. [30] found that the pain and intensity of a burn was associated with depression 6- and 12-months post-burn injury.

\section{Emotional issues}

Eight studies investigated emotional issues, mostly measured via the Child Behaviour Checklist (CBCL) [31, 47, 53, 56], the Strengths and Difficulties Questionnaire [5759], and the Burn Outcomes Questionnaire (BOQ) [60, 61]. Of the studies using the $\mathrm{CBCL}$, one study found that the children displayed a higher proportion of emotional problems than a normative sample [31], while another found their sample displayed fewer emotional problems than a normative one [47]. A third study using the CBCL reported that $7-9 \%$ of participants displayed emotional and behavioural problems [53], however, their results were not compared with normative data. Of the two studies that used the Strengths and Difficulties Questionnaire, one reported comparable results to normative data [59] whereas another study found their sample displayed more emotional problems than normative data [58]. Both studies reporting on the BOQ found significant associations between burns and emotional health $[60,61]$. Sveen et al. [60]) identified that pain, itch, and parental concern were associated with fear-avoidance and emotional health, and Warner et al. [61] found that larger burn sizes and facial burns decelerated the pace of emotional recovery [60]. Russell et al. [62] investigated the relationship between self-concept (perception of themselves and subsequent self-esteem) and emotional issues, and found that poorer self-concept was associated with emotional problems. 


\section{Self-esteem}

Findings were mixed with regards to self-esteem in children and adolescents who had experienced a burn injury. Three studies reported that their sample had healthy levels of self-esteem that were comparable to normative or control data of non-burned children $[37,55,58]$, whereas two studies reported low self-esteem in their sample $[36,62]$. Russell et al. [62] reported that children with an anxiety disorder also had lower self-concept. RiobuenoNaylor et al. [36] found that appearance concerns were associated with lower self-worth, and that the majority of adolescents receiving follow-up care after a burn were concerned with their appearance, although this wasn't related to burn size, location or gender of the adolescent.

\section{Quality of life}

Four studies examined Quality of Life (QoL) [58, 63-65]. Laitakari et al. [63] found that QoL was comparable for children who had experienced a burn injury when compared to control groups of non-burned children. Maskell et al. [58] and Weedon and Potterton [65] both found that QoL was lower for children or adolescents who had experienced a burn injury, with the latter study showing that children who were burned with hot water scored the poorest in terms of QoL. Murphy et al. [64] did not compare QoL to normative data, however did note that QoL 2.5-12.5years after the injury was poorer for children who sustained the injury after school entry (i.e. they were older).

\section{Self-harm}

One study investigated the incidence of self-harm following a burn injury and found that 10-26years after the injury, $2.7 \%$ of individuals who had experienced a burn injury had been admitted to hospital for self-harm, which is more than double the number of admissions from the non-burned control cohort [66].

\section{Suicidality}

Goodhew et al. [67] found that in their sample of adults who had sustained a burn injury as children, $11 \%$ had reported a suicide attempt in their lifetime. This study indicates individuals who sustained a burn in childhood have higher rates of suicide attempts compared to the general population, which is estimated to be between $3.2-4.5 \%[68,69]$.

\section{Mental health diagnoses}

Five studies reported on the incidence of mental health diagnoses following a pediatric burn injury [53, 66, 67, 70-72]. Bushroe et al. [70] reported that young children (0-4years) were most likely to receive a mental health diagnosis (8.56 risk-ratio) compared to older children
(10-14 years; 1.02 risk-ratio). Duke et al. [66] found that burn-injured pediatric patients were 2.6 times more likely to be admitted to hospital for psychiatric conditions 10-26 years after the injury, regardless of burn size or severity. This study also found that age was a factor, with older children (10-15years) being five times more likely to be admitted than younger children. Goodhew et al. [67] reported that $42 \%$ of their cohort received a mental health diagnosis in their lifetime, with female gender and burn visibility increasing this risk ratio. Thomas et al. [72] reported that $49 \%$ of their sample met criteria for one or more Cluster A (25.5\%), Cluster B (31.6\%), Cluster C (21.5\%), or Other (35.7\%; Personality Not Otherwise Specified, Passive Aggressive, or Depressive) personality disorders post a severe paediatric burn injury. Rosenberg et al. [53] investigated diagnosis based on burn type (electrical injury versus other burns) and found comparable incidences of mental health diagnoses at the acute stage post-injury for electrical injury compared to other burns. Specifically, they found that at acute presentation, $45-52 \%$ of the sample were experiencing anxiety, $31-51 \%$ were experiencing PTSD or Acute Stress Disorder, and 12-19\% were experiencing depression. Two-years postinjury these rates dropped to $10-14 \%$ for anxiety, $5-7 \%$ for PTSD, and 13-19\% for depression. Finally, De Young et al. [72] found that the children or adolescents with diagnosed PTSD after they had experienced a burn injury were more likely to also have Major Depressive Disorder, Oppositional Defiance Disorder, Seasonal Affective Disorder and Specific Phobia 1 month post-injury (73\% of cases). Six months post-injury, the children with PTSD were more likely to have an additional diagnosis of Attention Deficit Hyperactivity Disorder, Oppositional Defiance Disorder and Seasonal Affective Disorder (85\% of cases).

\section{Post-traumatic growth, resilience and coping}

Two studies examined post-traumatic growth (i.e. positive psychological change), resilience or coping in children and adolescents who had experienced a burn injury $[30,73]$. Nelson et al. [30] reported that pain from burns did not interrupt post-traumatic growth in children. Quezada et al. [73] showed that the children in their study had generally high levels of resilience following a burn injury, and that age was significantly associated with resilience, with younger children showing more resilience (as measured via the Resilience Questionnaire for children and adolescents) than older children.

\section{Results of qualitative studies}

Two of the three qualitative studies investigated the experiences of children or adolescents who experienced a burn, and the third investigated parent perception of 
their child or adolescent following a burn (see Table 2; [72-74]). Themes that arose in all studies were that the child experienced significant anxiety, stress, or "worry" after the burn incident.

\section{Risk of bias within studies}

Based on our criteria (see Table 3), we found that six independent studies met a high level of reliability and quality $(58,63,64,66,70,77)$. Only those six studies used a non-burn comparison group with which to compare psychological outcomes. Fourteen studies reported on longitudinal outcomes $(36,37,51-53,55,60-64,66,67,73)$, whereas the others reported on outcomes during the first 18 months following the injury.

Due to the heterogeneity of study designs, we were unable to conduct a meta-analysis on whether children and adolescents who experienced a burn injury went on to experience elevated rates or risk of psychopathology later in life.

\section{General discussion}

This study aimed to examine the research conducted on the psychological impact on children's mental health following paediatric burn injury from the years 2010-2020. In line with our hypothesis, we found that most studies reported elevated levels of psychopathology and psychological symptoms following paediatric burn injuries. However, findings were mixed for most mental health concerns and kinds of symptoms, except for increased anxiety symptoms and traumatic stress post burn injury.

Regarding psychological symptoms, studies reported that children generally experience more anxiety following a burn injury, that the anxiety they experience is more likely to be state-based (than trait-based), and the anxiety following a burn is associated with pain, the age at which the burn occurred (older children exhibit more difficulties), and the gender of the child (with girls more likely to report experiencing more anxiety than boys) [28, 30-37]. Qualitatively, we found that parents and children/adolescents both report the child or adolescent experiencing heightened anxiety after a burn compared to prior [75, 76, 78]. The majority of studies that investigated traumatic stress following a burn injury also reported children experiencing higher PTSD and acute stress symptoms, and that these symptoms could also be related to parental distress and the child's premorbid psychological problems [45, 47-49, 71].

In terms of mental health diagnoses, the six studies which reported these had different designs, making it difficult to generalise their results [53, 66, 67, 70-72]. There does appear to be evidence, however, of elevated risk for mental health diagnoses and hospitalisation following paediatric burn injury, and in particular diagnoses such as Anxiety Disorders, PTSD, Acute Stress Disorder,
Depression, and Personality Disorders were reported by the studies to be higher for this population.

Findings were mixed regarding depressive symptoms, emotional issues, self-esteem and QoL [30, 47, 51, 58-65, 77], and thus we cannot conclude on the experiences of children following a burn in these mental health concerns. Further, there were few studies investigating selfharm, resilience and suicidality following paediatric burn injury $[66,67,73]$, and further evidence is required for conclusions to be drawn in these domains.

\section{Limitations and future considerations}

There were methodological strengths and issues that arose from the studies in this review. Impressively, we found that $88 \%$ of the studies in our review used standardised measures, an improvement in comparison to the review by Bakker et al. [10], who reported that just $75 \%$ of included studies used standardised measures. This increase in the use of standardised measures allows for more reliable and generalisable findings. One of the main limitations we found was the issue of heterogeneity meaning we were unable to conduct a meta-analysis. Some studies reported lifetime diagnoses, and did not differentiate whether the diagnosis was pre- or post-burn injury [67], and other studies did not report on factors that would likely influence outcomes (such as whether the children received psychological support after the injury) [53]. Standardised reporting of mental health outcomes, for instance routinely collecting comorbid mental health diagnoses at admission or collecting standardised measures of depression and anxiety for all burns patients, would help address the issue of heterogeneity across studies. Further, more studies are needed in terms of long-term diagnostic outcomes of paediatric burns patients. The paper that reported the strongest evidence for long-term elevated rates of psychopathology was that of Bushroe et al. [70] who examined risk ratios for mental health diagnoses longitudinally and provided clear indication of the long-term impact of a paediatric burn injury. Most studies in our review reported on short-term (acute18 months) psychological outcomes following a burn injury, and it is difficult to determine causality in such studies. Despite this, we believe that the findings are still useful and able to inform clinical care and practice.

\section{Conclusions}

Given that most of the participants in the studies experienced increased anxiety, and that many experienced other psychological symptoms following a burn injury, it is clear that children and adolescents are particularly vulnerable following this type of traumatic injury. The longitudinal studies included in this review demonstrate that risk for psychopathology following a paediatric burn injury is much higher and ongoing than in 


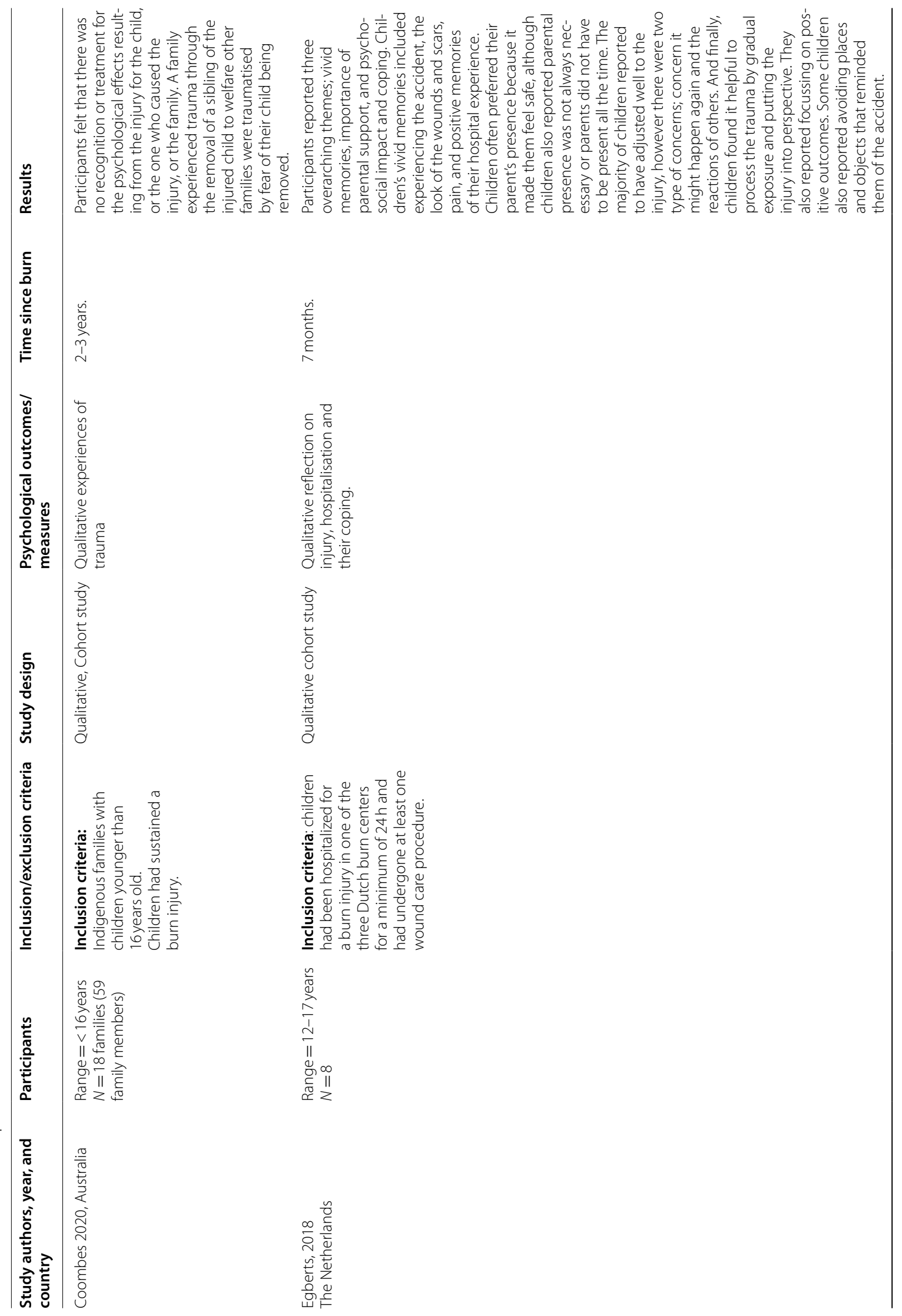




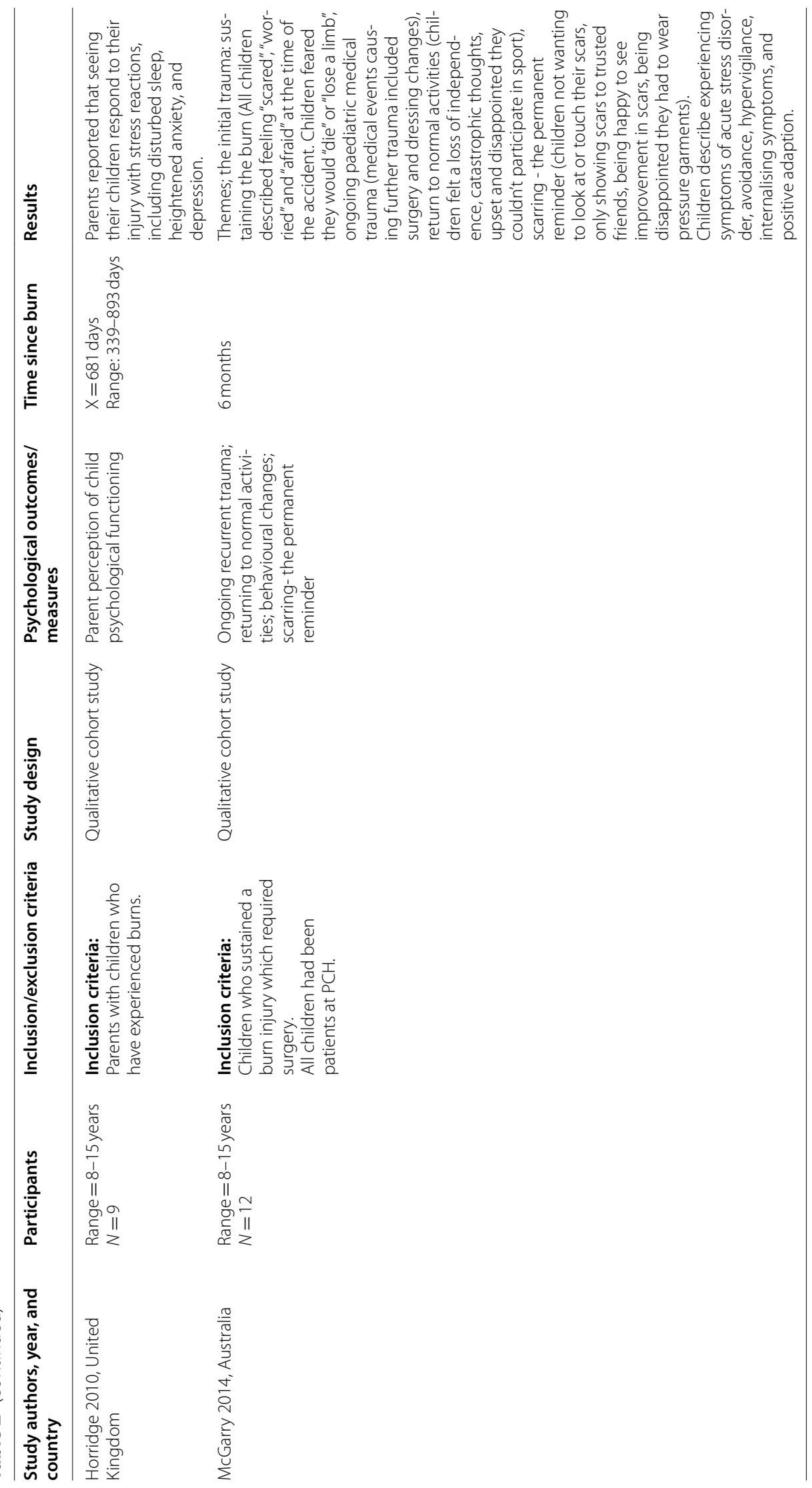


Table 3 Risk of bias and study quality assessment

\begin{tabular}{|c|c|c|c|c|c|c|}
\hline Study & $\begin{array}{l}\text { Non-burn } \\
\text { comparison } \\
\text { group? }\end{array}$ & $\begin{array}{l}\text { Validated measure or } \\
\text { confirmed diagnosis }\end{array}$ & $\begin{array}{l}\text { Power } \\
\text { analysis }\end{array}$ & $\begin{array}{l}\text { Appropriate } \\
\text { analysis }\end{array}$ & $\begin{array}{l}\text { Prospective or } \\
\text { longitudinal design } \\
(>18 \mathrm{mo})\end{array}$ & Total \\
\hline Boles, 2018 & 0 & 1 & 0 & 1 & 1 & 3 \\
\hline Brown, 2014 & 0 & 1 & 1 & 1 & 0 & 3 \\
\hline Brown, 2014 & 0 & 1 & 1 & 1 & 0 & 3 \\
\hline Bushroe, 2018 & 1 & 1 & 0 & 1 & 0 & 4 \\
\hline Chester, 2018 & 0 & 1 & 1 & 1 & 0 & 3 \\
\hline Chrapusta, 2014 & 0 & 1 & 0 & 1 & 0 & 2 \\
\hline Conn, 2017 & 0 & 0 & 1 & 1 & 0 & 2 \\
\hline DeYoung, 2012 & 0 & 1 & 0 & 1 & 0 & 2 \\
\hline DeYoung, 2014 & 0 & 1 & 0 & 1 & 0 & 2 \\
\hline Duke, 2018 & 1 & 1 & 0 & 1 & 1 & 4 \\
\hline Enlow, 2019 & 0 & 1 & 1 & 1 & 0 & 3 \\
\hline Goodhew, 2014 & 0 & 1 & 0 & 1 & 1 & 3 \\
\hline Graf, 2011 & 0 & 1 & 0 & 1 & 0 & 2 \\
\hline Haag, 2017 & 0 & 1 & 0 & 1 & 0 & 3 \\
\hline Hyland, 2015 & 0 & 1 & 1 & 1 & 0 & 3 \\
\hline Jeffs, 2014 & 0 & 1 & 1 & 1 & 0 & 3 \\
\hline Khadra, 2018 & 0 & 1 & 1 & 1 & 0 & 3 \\
\hline Laitakari, 2015 & 1 & 1 & 0 & 1 & 1 & 4 \\
\hline Maskell, 2013, 2014 & 1 & 1 & 1 & 1 & 0 & 4 \\
\hline Murphy, 2015 & 1 & 1 & 0 & 1 & 1 & 4 \\
\hline Nelson, 2020 & 0 & 1 & 0 & 1 & 0 & 2 \\
\hline Nicolosi, 2013 & 0 & 1 & 0 & 1 & 1 & 3 \\
\hline Nodoushani, 2018 & 0 & 0 & 0 & 0 & 1 & 1 \\
\hline Pardo, 2010 & 0 & 1 & 0 & 1 & 0 & 2 \\
\hline Parlak Gurol, 2010 & 0 & 1 & 0 & 1 & 0 & 2 \\
\hline Quezada, 2016 & 0 & 1 & 0 & 1 & 1 & 3 \\
\hline Rezazadeh, 2020 & 0 & 1 & 1 & 1 & 0 & 3 \\
\hline Rimmer, 2014a/b & 0 & 1 & 0 & 1 & 0 & 2 \\
\hline Riobueno-Naylor, 2020 & 0 & 1 & 0 & 1 & 1 & 3 \\
\hline Rosenberg, 2015 & 0 & 1 & 0 & 1 & 1 & 3 \\
\hline Russell, 2013 & 0 & 1 & 0 & 1 & 1 & 3 \\
\hline Sharp, 2010 & 0 & 1 & 1 & 1 & 0 & 3 \\
\hline Stoddard, 2011 & 0 & 1 & 0 & 1 & 0 & 2 \\
\hline Sveen, 2012 & 0 & 1 & 0 & 1 & 1 & 3 \\
\hline Thomas, 2012 & 0 & 1 & 0 & 1 & 0 & 2 \\
\hline Tropez-Arceneaux, 2017 & 0 & 1 & 0 & 0 & 1 & 2 \\
\hline Warner, 2012 & 0 & 1 & 0 & 1 & 1 & 3 \\
\hline Weedon, 2011 & 0 & 1 & 0 & 1 & 0 & 3 \\
\hline Willebrand, 2011 & 0 & 1 & 0 & 1 & 0 & 2 \\
\hline
\end{tabular}

Note: $1=$ present, $0=$ not present

the general population, which suggests that psychological recovery for these children and adolescents needs to be an area of focus in the future. The clinical care teams involved in a child's recovery from a burn need to support psychological recovery for the child and the family to promote optimal outcomes. Ideally, the clinical care team should include consultation from mental health professionals. Our findings also demonstrate that factors in a child's life (such as parental distress, 
age, and gender) may influence their psychological recovery and should be taken into consideration by the clinical care team.

\author{
Abbreviations \\ PTSD: Post-traumatic Stress Disorder; PRISMA: Preferred Reporting Items for \\ Systematic Reviews and Meta-Analyses; RCT: Randomised Controlled Trial; \\ VAS-A: Visual Analog Scale - Anxiety; CBCL: Child Behaviour Checklist; BOQ: \\ Burns Outcomes Questionnaire; QoL: Quality of Life.
}

\section{Acknowledgements}

AL is supported by an NHMRC Career Development Fellowship (\#1148793).

\section{Authors' contributions}

AW, FMW and HM conceived of the study. AW conducted the searches. Screening was completed by AW and NTMH. AL acted as a consensus reviewer. AW extracted data and assessed quality of the included papers, NTMH and MM double checked this process. AW was responsible for the data analysis, with input from HM, AL, IB, MM and LM. The initial draft of the manuscript was prepared by AW, then circulated among all authors for critical revision. The author(s) read and approved the final manuscript.

\section{Funding}

This work was supported by a Channel 7 Telethon Trust grant.

\section{Availability of data and materials}

Data was available to authors via University databases. The datasets used and/ or analysed during the current study available from the corresponding author on reasonable request.

\section{Declarations}

\section{Ethics approval and consent for publication}

Ethical approval was not required, as no primary data were collected as part of this study. Consent was therefore not required for publication.

\section{Competing interests}

AL is supported by an NHMRC Career Development Fellowship (\#1148793). NTMH is supported by a Forrest Fellowship. AW, MM, LM, HM, FMW and IB declare no competing interests.

\section{Author details}

${ }^{1}$ Telethon Kids Institute, Perth Children's Hospital, 15 Hospital Avenue, Nedlands, Australia. ${ }^{2}$ The University of Western Australia, Perth, Australia. ${ }^{3}$ Fiona Wood Foundation, Perth, Australia; Child and Adolescent Health Service, Perth Children's Hospital, University of Western Australia, Perth, Western Australia, Australia. ${ }^{4}$ Fiona Wood Foundation, Perth, Australia.

Received: 23 August 2021 Accepted: 23 November 2021

Published online: 14 December 2021

\section{References}

1. Australian Institute of Health and Welfare. Hospitalised burn injuries Australia [Internet]. Australian Institute of Health and Welfare. 2013 [cited 2020 Oct 19]. Available from: https://www.aihw.gov.au/reports/injury/ hospitalised-burn-injuries-australia-2013-14/contents/summary

2. Toon MH, Maybauer DM, Arceneaux LL, Fraser JF, Meyer W, Runge A, et al. Children with burn injuries-assessment of trauma, neglect, violence and abuse. J Inj Violence Res. 2011:3(2):98-110.

3. Chong HP, Quinn L, Cooksey R, Molony D, Jeeves A, Lodge M, et al. Mortality in paediatric burns at the Women's and Children's hospital (WCH), Adelaide, South Australia: 1960-2017. Burns. 2020;46(1):207-12.

4. Yarbrough DR. Improving survival in the burned patient. J S C Med Assoc 1975. 1990 Jun;86(6):347-9.

5. De Sousa A. Psychological aspects of Paediatric burns (a clinical review). Ann Burns Fire Disasters. 2010:23(3):155-9.
6. Martin-Herz SP, Thurber CA, Patterson DR. Psychological principles of burn wound pain in children II: treatment applications. J Burn Care Rehabil. 2000:21(5):458-72.

7. Andreasen NJ, Noyes R, Hartford CE. Factors influencing adjustment of burn patients during hospitalization. Psychosom Med. 1972;34(6):517-25.

8. Andreasen NJ, Hartford CE, Knott JR, Canter DA. EEG changes associated with burn delirium. Dis Nerv Syst. 1977;38(1):27-31.

9. Van Loey NEE, Van Son MJM. Psychopathology and psychological problems in patients with burn scars: epidemiology and management. Am J Clin Dermatol. 2003;4(4):245-72.

10. Bakker A, Maertens KJP, Van Son MJM, Van Loey NEE. Psychological consequences of pediatric burns from a child and family perspective: a review of the empirical literature. Clin Psychol Rev. 2013;33(3):361-71.

11. Dise-Lewis JE. A Developmental Perspective on Psychological Principles of Burn Care: J Burn Care Rehabil. 2001;22(3):255-60.

12. Landolt MA, Buehlmann C, Maag T, Schiestl C. Brief report: quality of life is impaired in pediatric burn survivors with posttraumatic stress disorder. J Pediatr Psychol. 2020;34(1):14-21.

13. Saxe GN, Stoddard FJ, Hall E, Chawla N, Lopez C, Sheridan R, et al. Pathways to PTSD, part I: children with burns. Am J Psychiatry. 2005;6.

14. Young ACD, Kenardy JA, Cobham VE, Kimble R. Prevalence, comorbidity and course of trauma reactions in young burn-injured children. J Child Psychol Psychiatry. 2011;8.

15. Stoddard FJ, Ronfeldt H, Kagan J, Drake JE, Snidman N, Murphy JM, et al. Young burned children: the course of acute stress and physiological and behavioral responses. Am J Psychiatry. 2006;7.

16. Meyer WJ, Robert R, Murphy L, Blakeney PE. Evaluating the psychosocial adjustment of 2- and 3-year-old pediatric burn survivors. J Burn Care Rehabil. 2000;21(2):179-84.

17. Piazza-Waggoner C, Dotson C, Adams CD, Joseph K, Goldfarb IW, Slater H. Preinjury Behavioral and Emotional Problems Among Pediatric Burn Patients. J Burn Care Rehabil. 2005;26(4):371-8.

18. Stoddard FJ, Norman DK, Murphy MJ, Beardslee WR. Psychiatric outcome of burned children and adolescents. J Am Acad Child Adolesc Psychiatry. 1989;28(4):589-95.

19. Landolt MA, Grubenmann S, Meuli M. Family Impact Greatest: Predictors of Quality of Life and Psychological Adjustment in Pediatric Burn Survivors. J Trauma Inj Infect Crit Care. 2002:53(6):1146-51.

20. Liberati A, Altman DG, Tetzlaff J, Mulrow C, Gøtzsche PC, loannidis JPA, et al. The PRISMA statement for reporting systematic reviews and metaanalyses of studies that evaluate health care interventions: explanation and elaboration. J Clin Epidemiol. 2009:62(10):e1-34.

21. Veritas health innovation. Covidence systematic review software [Internet]. Covidence. [cited 2020 Oct 22]. Available from: https://app.covid ence.org/

22. National Heart Lung and Blood Institute. Study Quality Assessment Tools: Study quality assessment tool for observational cohort and cross-sectional studies [Internet]. : https://www.nhlbi.nih.gov/health-topics/studyqualityassessment-tools. 38. Abrutyn S, Mueller AS. 2020 [cited 2020 Oct 22]. Available from: https://www.nhlbi.nih.gov/health-topics/study-quali ty-assessment-tools

23. Brown NJ, Kimble RM, Rodger S, Ware RS, Cuttle L. Play and heal: randomized controlled trial of ditto ${ }^{\text {TM }}$ intervention efficacy on improving re-epithelialization in pediatric burns. Burns. 2014;40(2):204-13.

24. Chester SJ, Tyack Z, De Young A, Kipping B, Griffin B, Stockton K, et al. Efficacy of hypnosis on pain, wound-healing, anxiety, and stress in children with acute burn injuries: a randomized controlled trial. Pain. 2018:159(9):1790-801.

25. Chrapusta A, Pąchalska M. Evaluation of differences in health-related quality of life during the treatment of post-burn scars in pre-school and school children. Ann Agric Environ Med. 2014;21(4):5.

26. Conn AS, Hall MS, Quinn K, Wiggins B, Memmott C, Brusseau TA. An examination of a yoga intervention with pediatric burn survivors. J Burn Care Res. 2017:38(1):e337-42

27. Hyland EJ, D'Cruz R, Harvey JG, Moir J, Parkinson C, Holland AJA. An assessment of early child life therapy pain and anxiety management: a prospective randomised controlled trial. Burns. 2015;41(8):1642-52.

28. Jeffs D, Dorman D, Brown S, Files A, Graves T, Kirk E, et al. Effect of Virtual Reality on Adolescent Pain During Burn Wound Care: J Burn Care Res. 2014;35(5):395-408 
29. Khadra C, Ballard A, Déry J, Paquin D, Fortin J-S, Perreault I, et al. Projector-based virtual reality dome environment for procedural pain and anxiety in young children with burn injuries: a pilot study. J Pain Res. 2018;11:343-53.

30. Nelson S, Uhl K, Wright LA, Logan D. Pain is associated with increased physical and psychosocial impairment in youth with a history of burn injuries. J Pain. 2020;21(3-4):355-63.

31. Pardo GD, García IM, Gómez-Cía T. Psychological Effects Observed in Child Burn Patients During the Acute Phase of Hospitalization and Comparison With Pediatric Patients Awaiting Surgery. J Burn Care Res. 2010;31(4):569-78.

32. Parlak Gürol A, Polat S, Nuran AM. Itching, Pain, and Anxiety Levels Are Reduced With Massage Therapy in Burned Adolescents. J Burn Care Res. 2010;31(3):429-32.

33. Rezazadeh H, Froutan R, Ahmad Abadi A, Mazloum SR, Moghaddam K. Effects of art therapy program on anxiety and depression among 6-12-year-old burned children. Open Access Maced J Med Sci. 2020;8(B):126-32.

34. Rimmer RB, Bay RC, Alam NB, Sadler IJ, Hansen L, Foster KN, et al. BurnInjured Youth May Be at Increased Risk for Long-Term Anxiety Disorders: J Burn Care Res 2014;35(2):154-161.

35. Rimmer RB, Bay RC, Sadler IJ, Alam NB, Foster KN, Caruso DM. Parent vs burn-injured child self-report: contributions to a better understanding of anxiety levels. J Burn Care Res. 2014;35(4):296-302.

36. Riobueno-Naylor A, Williamson H, Canenguez K, Kogosov A, Drexler A, Sadeq F, et al. Appearance Concerns, Psychosocial Outcomes, and the Feasibility of Implementing an Online Intervention for Adolescents Receiving Outpatient Burn Care. J Burn Care Res. 2020 Jun 28;iraa108.

37. Tropez-Arceneaux LL, Castillo Alaniz AT, Lucia Icaza I, Alejandra Murillo E. The Psychological Impact of First Burn Camp in Nicaragua: J Burn Care Res 2017:38(1):e1-e7.

38. AlHW. Australia's children, Children with mental illness [Internet]. Australian Institute of Health and Welfare. 2020 [cited 2021 Feb 3]. Available from: https://www.aihw.gov.au/reports/children-youth/australias-child ren/contents/health/children-with-mental-illness

39. Elliott CH, Jay SM, Woody P. An observation scale for measuring children's distress during medical procedures. J Pediatr Psychol. 1987;12(4):543-51.

40. Knight RG, Waal-Manning HJ, Spears GF. Some norms and reliability data for the state--trait anxiety inventory and the Zung self-rating depression scale. Br J Clin Psychol. 1983;22(Pt 4):245-9.

41. Julian LJ. Measures of Anxiety. Arthritis Care Res [Internet]. 2011 Nov [cited 2021 Feb 3];63(0 11). Available from: https://www.ncbi.nlm.nih. gov/pmc/articles/PMC3879951/

42. Beck AT, Epstein N, Brown G, Steer RA. An inventory for measuring clinical anxiety: psychometric properties. J Consult Clin Psychol. 1988;56(6):893-7.

43. Spence MJ, Moore DS. Categorization of infant-directed speech: development from 4 to 6 months. Dev Psychobiol. 2003;42(1):97-109.

44. Brown NJ, Kimble RM, Rodger S, Ware RS, McWhinney BC, Ungerer JPJ, et al. Biological markers of stress in pediatric acute burn injury. Burns. 2014;40(5):887-95.

45. De Young AC, Hendrikz J. Kenardy J.a. JA, Cobham VE, Kimble RM. prospective evaluation of parent distress following pediatric burns and identification of risk factors for young child and parent posttraumatic stress disorder. J Child Adolesc Psychopharmacol. 2014;24(1):9-17.

46. Enlow PT, Brown Kirschman KJ, Mentrikoski J, Szabo MM, Butz C, Aballay $\mathrm{AM}$, et al. The role of youth coping strategies and caregiver psychopathology in predicting posttraumatic stress symptoms in pediatric burn survivors. J Burn Care Res. 2019;40(5):620-6.

47. Graf A, Schiestl C, Landolt MA. Posttraumatic stress and behavior problems in infants and toddlers with burns. J Pediatr Psychol. 2011;36(8):923-31.

48. Haag A-C, Landolt MA. Young Children's acute stress after a burn injury: disentangling the role of injury severity and parental acute stress. J Pediatr Psychol. 2017;42(8):861-70.

49. Sharp S, Thomas C, Rosenberg L, Rosenberg M, Meyer W. Propranolol Does Not Reduce Risk for Acute Stress Disorder in Pediatric Burn Trauma. J Trauma Inj Infect Crit Care. 2010;68(1):193-7.

50. Stoddard FJ. Therapeutic play in the diagnosis and treatment of hospitalized children recovering from acute burns. J Am Acad Child Adolesc Psychiatry. 2017;56(10):S118.
51. Boles R, Gawaziuk JP, Cristall N, Logsetty S. Pediatric frostbite: a 10-year single-center retrospective study. Burns. 2018;44(7):1844-50.

52. Nodoushani A.Y., Murphy J.M., Wang S.L., Stoddard FJ, Kazis L., Lydon M., et al. Prevalence of depressive symptoms over time in pediatric burn survivors. J Burn Care Res. 2018;39(Supplement 1):S102.

53. Rosenberg M, Mehta N, Rosenberg L, Ramirez M, Meyer WJ, Herndon DN, et al. Immediate and long-term psychological problems for survivors of severe pediatric electrical injury. Burns. 2015 Dec;41(8):1823-30.

54. Kovacs M. Children's depression inventory. MHS; 2011.

55. Nicolosi JT, De Carvalho VF, Sabates AL. A quantitative, cross-sectional study of depression and self-esteem in teenage and young adult burn victims in rehabilitation. Ostomy Wound Manag. 2013;59(9):22-9.

56. Achenbach TM, Rescorla LA. Manual for the ASEBA School-age Forms \& Profiles. Burlington, VT: University of Vermont, Research Center for Children, Youth and Families; 2013.

57. Goodman R. Psychometric properties of the strengths and difficulties questionnaire. J Am Acad Child Adolesc Psychiatry. 2001;40(11):1337-45.

58. Maskell J, Newcombe P, Martin G, Kimble R. Psychosocial Functioning Differences in Pediatric Burn Survivors Compared With Healthy Norms: J Burn Care Res 2013;34(4):465-476.

59. Willebrand M, Sveen J, Ramklint M, Bergquist M, Huss F, Sjöberg F. Psychological problems in children with burns-parents' reports on the strengths and difficulties questionnaire. Burns. 2011 Dec;37(8):1309-16.

60. Sveen J, Huss F, Sjoberg F, Willebrand M. Psychometric properties of the swedish version of the burn outcomes questionnaire for children aged 5 to 18 years. J Burn Care Res. 2012;33(6):e286-94.

61. Warner P, Stubbs TK, Kagan RJ, Herndon DN, Palmieri TL, Kazis LE, et al. The effects of facial burns on health outcomes in children aged 5 to 18 years: J trauma acute care Surg. Sep. 2012;73:S189-96.

62. Russell W, Robert RS, Thomas CR, Holzer CE, Blakeney P, Meyer WJ. SelfPerceptions of Young Adults Who Survived Severe Childhood Burn Injury: J Burn Care Res. 2013;34(4):394-402.

63. Laitakari E, Koljonen V, Pyorala S, Rintala R, Roine RP, Sintonen H. The longterm health-related quality of life in children treated for burns as infants 5-9 years earlier. Burns. 2015;41(6):1186-92.

64. Murphy ME, Holzer CE, Richardson LM, Epperson K, Ojeda S, Martinez $E M$, et al. Quality of life of young adult survivors of pediatric burns using world health organization disability assessment scale II and burn specific health scale-brief: a comparison. J Burn Care Res. 2015;36(5):521-33.

65. Weedon M, Potterton J. Socio-economic and clinical factors predictive of paediatric quality of life post burn. Burns. 2011;37(4):572-9.

66. Duke JM, Randall SM, Vetrichevvel TP, McGarry S, Boyd JH, Rea S, et al. Long-term mental health outcomes after unintentional burns sustained during childhood: a retrospective cohort study. Burns Trauma. 2018 Dec 1;6:s41038-018-0134-z.

67. Goodhew F, Van Hooff M, Sparnon A, Roberts R, Baur J, Saccone EJ, et al. Psychiatric outcomes amongst adult survivors of childhood burns. Burns. 2014;40(6):1079-88.

68. Johnston AK, Pirkis JE, Burgess PM. Suicidal thoughts and Behaviours among Australian adults: findings from the 2007 National Survey of mental health and wellbeing. Aust N Z J Psychiatry. 2009 Jul 1;43(7):635-43.

69. De Leo D, Cerin E, Spathonis K, Burgis S. Lifetime risk of suicide ideation and attempts in an Australian community: prevalence, suicidal process, and help-seeking behaviour. J Affect Disord. 2005 Jun;86(2-3):215-24.

70. Bushroe KM, Hade EM, McCarthy TA, Bridge JA, Leonard JC. Mental Health after Unintentional Injury in a Pediatric Managed-Medicaid Population. J Pediatr. 2018 Aug;199:29-34.e16.

71. De Young AC, Kenardy JA, Cobham VE, Kimble R. Prevalence, comorbidity and course of trauma reactions in young burn-injured children. J Child Psychol Psychiatry. 2012;53(1):56-63.

72. Thomas CR, Russell W, Robert RS, Holzer CE, Blakeney P, Meyer WJ. Personality disorders in Young adult survivors of pediatric burn injury. J Personal Disord. 2012;26(2):255-66.

73. Quezada L, González MT, Mecott GA. Explanatory Model of Resilience in Pediatric Burn Survivors: J Burn Care Res. 2016;37(4):216-25.

74. Coombes J, Hunter K, Mackean T, Ivers R. The journey of aftercare for Australia's first nations families whose child had sustained a burn injury: a qualitative study. BMC Health Serv Res. 2020;20(1):536. 
75. Horridge G, Cohen K, Gaskell S. BurnEd: parental, psychological and social factors influencing a burn-injured child's return to education. Burns. 2010;36(5):630-8.

76. McGarry S, Elliott C, McDonald A, Valentine J, Wood F, Girdler S. Paediatric burns: from the voice of the child. Burns. 2014;40(4):606-15.

77. Maskell J, Newcombe P, Martin G, Kimble R. Psychological and psychosocial functioning of children with burn scarring using cosmetic camouflage: a multi-Centre prospective randomised controlled trial. Burns. 2014:40(1):135-49.

78. Egberts MR, van de Schoot R, Geenen R, Van Loey NEE. Parents' posttraumatic stress after burns in their school-aged child: a prospective study. Health Psychol. 2017;36(5):419-28.

\section{Publisher's Note}

Springer Nature remains neutral with regard to jurisdictional claims in published maps and institutional affiliations.

- fast, convenient online submission

- thorough peer review by experienced researchers in your field

- rapid publication on acceptance

- support for research data, including large and complex data types

- gold Open Access which fosters wider collaboration and increased citations

- maximum visibility for your research: over $100 \mathrm{M}$ website views per year

At $\mathrm{BMC}$, research is always in progress.

Learn more biomedcentral.com/submissions 